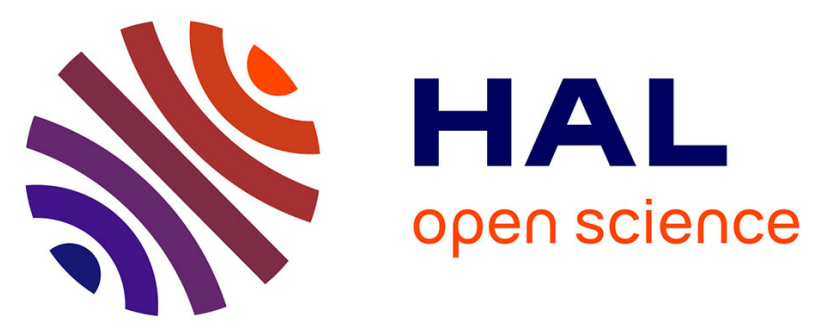

\title{
A New Route to NAG-NAM Disaccharide, an Important Building Block for Peptidoglycan Oligomer Synthesis
} Antoine Rousseau, Emeline Richard, Isabelle Jeacomine, Sylvie Armand, Sébastien Fort, Sylvain Cottaz

\section{- To cite this version:}

Antoine Rousseau, Emeline Richard, Isabelle Jeacomine, Sylvie Armand, Sébastien Fort, et al.. A New Route to NAG-NAM Disaccharide, an Important Building Block for Peptidoglycan Oligomer Synthesis. Asian Journal of Organic Chemistry, In press, 10.1002/ajoc.202100547 . hal-03374259

HAL Id: hal-03374259

https://hal.science/hal-03374259

Submitted on 12 Oct 2021

HAL is a multi-disciplinary open access archive for the deposit and dissemination of scientific research documents, whether they are published or not. The documents may come from teaching and research institutions in France or abroad, or from public or private research centers.
L'archive ouverte pluridisciplinaire HAL, est destinée au dépôt et à la diffusion de documents scientifiques de niveau recherche, publiés ou non, émanant des établissements d'enseignement et de recherche français ou étrangers, des laboratoires publics ou privés. 


\title{
A New Route to NAG-NAM Disaccharide, an Important Building Block for Peptidoglycan Oligomer Synthesis
}

Antoine Rousseau, ${ }^{[\mathrm{a}]}$ Dr. Emeline Richard ${ }^{[\mathrm{a}]}$ Isabelle Jeacomine,${ }^{[\mathrm{a}]}$ Dr. Sylvie Armand, ${ }^{[\mathrm{a}]}$ Dr. Sébastien Fort, ${ }^{[\mathrm{a}]}$ and Prof. Sylvain $\operatorname{Cottaz}^{*[\mathrm{a}]}$

[a] Univ Grenoble Alpes, CNRS, CERMAV

38000 Grenoble (France)

E-mail: sebastien.fort@cermav.cnrs.fr

E-mail: sylvain.cottaz@cermav.cnrs.fr

\begin{abstract}
Peptidoglycan oligomers constitute precious tools for the biochemical and structural studies of enzymes involved in the bacterial cell wall metabolism. In this study we show that an unprecedented selective Zemplén de- $O$-acetylation of benzyl chitinbioside peracetate leads to a fast and efficient route to $N$-acetylmuramyl $\beta(1 \rightarrow 4) \quad N$ acetylglucosaminide disaccharide, a central building block for the synthesis of peptidoglycan oligomers. Starting from known benzyl chitinbioside, NAG-NAM disaccharide pentapeptide is prepared in seven steps with an overall yield of $12 \%$.
\end{abstract}

Keywords : peptidoglycan, muropeptide, oligosaccharide, chitinbiose, selective deacylation

Peptidoglycan (PG) is a complex bacterial polymer which plays a major role in the cell shape, structure, growing, division and host-cell interaction. Its biosynthesis, modification and 
recycling during cell life cycle are governed by a myriad of enzymes representing the main target for antibiotics development, i.e. peptide ligases, racemases, transpeptidases, endopeptidases, carboxypeptidases, glycosyltransferases and transglycosylases, translocases. ${ }^{[1]}$ Antibiotic resistance being forecast as a major issue in the next decades, ${ }^{[2]}$ the need for a better comprehension of biochemical events associated with PG is of primary importance.

Pure and well-defined oligomers are tools of choice for the biochemical and structural characterization of proteins interacting with peptidoglycan. Although PG and fragments (muropeptides) can be extracted and purified from bacterial culture, the resulting structural heterogeneity hampers their use as substrates or ligands for biochemical studies. ${ }^{[3]}$ Mixture of PG oligomers have been prepared in minute quantities by lipid II enzymatic polymerization using a mutant transglycosylase $\mathrm{SgtB}^{\mathrm{Y} 181 \mathrm{D}}$ with reduced activity leading to short oligomers. ${ }^{[4]}$ Chemical synthesis is the most common approach to get multimilligram amounts of these compounds. Top-down strategy starting from chitin, a $\beta(1 \rightarrow 4) \mathrm{N}$-acetylglucosaminyl polymer found in crustaceans and arthropods, has been recently explored. ${ }^{[5]}$ Bottom-up synthesis from $\mathrm{N}$-acetylglucosamine monomer remains the only route giving access to PG oligomers up to octamer pentapeptide. ${ }^{[6 a-c]}$ All these approaches share a $N$-acetylmuramyl $\beta(1 \rightarrow 4) \mathrm{N}$ acetylglucosaminide (NAG-NAM) disaccharide as central synthon for further elongation.

Our interest lies in the design of enzymatic strategies for the synthesis of complex oligosaccharides and polysaccharides of biological importance, in particular by exploiting the transglycosylation activities of mutant glycoside hydrolases (the so-called glycosynthases). ${ }^{[7]}$ To achieve this goal, a straightforward access to the NAG-NAM disaccharide unit of PGN is needed. 
The preparation of NAG-NAM is well documented, and implies the stereoselective glycosylation of appropriately protected glucosamine as glycosyl donor and muramic acid derivative or its precursor as an acceptor. This methodology has recently been summarized by Marques et al. who proposed a rapid access to NAG-NAM precursor starting from chitinbiose disaccharide and avoiding the tricky step of monosaccharide coupling. ${ }^{[8]}$ Starting from di- $N$ TFA-S-tolylchitobioside, this original strategy necessitates in the first and key step the discrimination of $O-3^{\mathrm{I}}$ position with the help of 1,2-diacetal methodology allowing the selective protection of $O-3^{\mathrm{II}}$ and $O-4^{\mathrm{II}}$ positions. ${ }^{[9]}$ Then protection of $O-6^{\mathrm{I}}$ and O- $6^{\mathrm{II}}$ positions can be achieved with bulky silyl protecting group such as tert-butyldimethylsilyl (TBDMS). After a last step of alkylation of remaining free $O-3^{\mathrm{I}}$ position with the lactyl moiety, the overall yield of fully protected NAG-NAM disaccharide from chitinbioside was $7 \%$ in four steps, constituting a considerable improvement of access to this important synthon.

Inspired by this recent progress we decided to explore an even more direct approach, by investigating the selective deprotection of chitinbioside peracetate. The regioselective de$O$-acetylation of mono- and oligosaccharides generally employs the capability of esterases to utilize acetylated carbohydrates in hydro-organic media. ${ }^{[10]}$ Esterases generally remove acetates from monosaccharides at $O-6$ and $O-1$ positions, and the deprotection of $O-4$ or $O-3$ positions can be achieved by subsequent controlled migration steps. In the case of di- or oligosaccharides, the selective deprotection of hydroxy groups other than those of the reducing end is not possible. Consequently, this methodology is inappropriate for freeing $O-3$ position on the reducing unit of chitinbiose peracetate in the view of preparing a NAG-NAM disaccharide. In another approach several so-called "anomalous" Zemplén de- $O$-acylations have been reported on mono- and oligosaccharides, with as common feature that the oxygen reluctant to deacylation is vicinal to a non-oxygenated or non-acetylated position. ${ }^{[11]}$ This 
observation encouraged us to evaluate the behavior of benzyl $\beta$-chitinbioside peracetate under controlled Zemplén deacetylation conditions.

When conducted overnight at room temperature using $0.17 \mathrm{M} \mathrm{MeONa}$ in a DCM$\mathrm{MeOH}$ mixture, de- $O$-acetylation was total, affording the unprotected disaccharide 1 . Running the reaction with $0.1 \mathrm{M} \mathrm{MeONa}$ in $\mathrm{MeOH}$ under controlled conditions $\left(0-5^{\circ} \mathrm{C}, 0.5-1 \mathrm{~h}\right)$ allowed to accumulate a partially deprotected intermediate as major product. This compound, 2, was isolated and characterized. MS analysis showed a molecular ion $[\mathrm{M}+\mathrm{H}]^{+}$at $\mathrm{m} / \mathrm{z} 557$ corresponding to benzyl $\beta$-chitinbioside mono- $O$-acetate, suggesting that a partial de- $O$ acetylation has occurred, with a single $O$-acetyl group remaining on the disaccharide. ${ }^{1} \mathrm{H}$ and ${ }^{13} \mathrm{C}$ NMR data in $\mathrm{D}_{2} \mathrm{O}$ of the mono- $O$-acetylated product were compared with $\mathbf{1}$ (Table 1 ). In first instance a remaining $O$-acetyl group is clearly distinguished at $2.15 \mathrm{ppm}$ and $20.4 \mathrm{ppm}$ in ${ }^{1} \mathrm{H}$ and ${ }^{13} \mathrm{C}$ NMR respectively. ${ }^{1} \mathrm{H}$ NMR spectra indicates a considerable increase shielding for $\mathrm{H}-3^{\mathrm{I}}$ from $3.64 \mathrm{ppm}$ for $\mathbf{1}$ to $5.08 \mathrm{ppm}$ for 2 . At the same time ${ }^{13} \mathrm{C}$ NMR shows a $1.8 \mathrm{ppm}$ increase shielding for $\mathrm{C}-3^{\mathrm{I}}$ together with a downfield shift for $\mathrm{C}-2^{\mathrm{I}}$ and $\mathrm{C}-4^{\mathrm{I}}$. In agreement with the data collected by Bundle et al. on 3-O-acetyl- $N$-acetylglucosamine, ${ }^{[12]}$ these data taken together strongly suggest that a partial $O$-deacetylation has occurred, with an $O$-acetyl group remaining at $O-3^{\mathrm{I}}$.

Table 1. Selected ${ }^{13} \mathrm{C} /{ }^{1} \mathrm{H}$ chemical shifts (ppm) for the reducing unit of benzyl $\beta$ chitinbioside $\mathbf{1}$ and $3^{\mathrm{I}}$ - $O$-acetyl derivative 2 .

\begin{tabular}{|c|c|c|c|}
\hline Compound & $\mathrm{C}^{\prime} 2^{\prime} / \mathrm{H}-2^{\prime}$ & $\mathrm{C}-3^{\prime} / \mathrm{H}-3^{\prime}$ & $\mathrm{C}-4^{\prime} / \mathrm{H}-4^{\prime}$ \\
\hline $\mathbf{1}$ & $54.0 / 3.75$ & $72.3 / 3.64$ & $79.5 / 3.61$ \\
\hline $\mathbf{2}$ & $53.9 / 3.90$ & $74.1 / 5.08$ & $75.8 / 3.91$ \\
\hline
\end{tabular}


This hypothesis was confirmed by the very good correlation observed between the carbonyl of $O$-acetyl group and $\mathrm{H}-3^{\mathrm{I}}$ with the help of ${ }^{1} \mathrm{H}^{-13} \mathrm{C}$ HMBC NMR experiment (Supporting Information).

As judged by TLC, benzyl $3^{\mathrm{I}}$ - $O$-acetyl- $\beta$-chitinbioside 2 was pure enough to be used in the next step without purification. Remaining free hydroxy groups were silylated with TBDMS group giving fully protected disaccharide 3 with a yield of $67 \%$ over the two steps (Scheme 1).
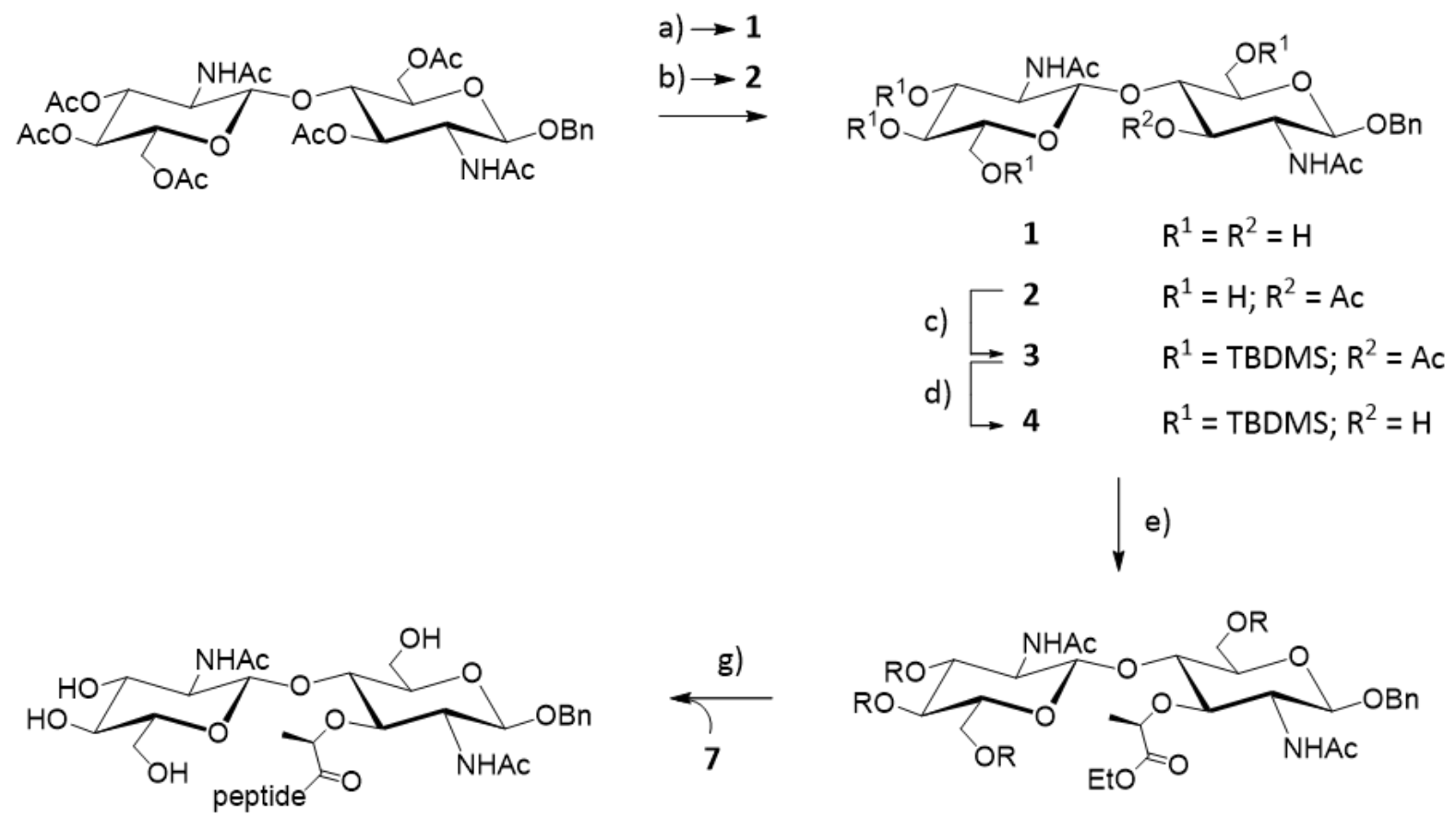

peptide = L-Ala-D-iso-Glu-L-Lys-D-Ala-D-Ala
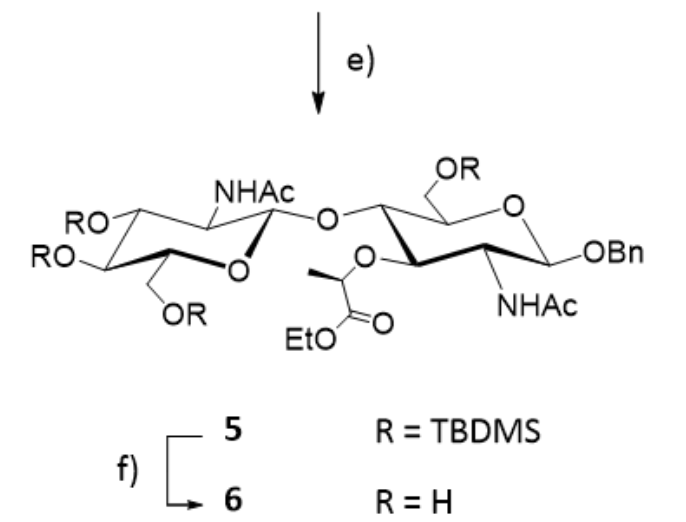

Scheme 1. Synthesis of benzyl $\beta$-NAG-NAM pentapeptide. a) MeONa 0.17 M, DCM, $\mathrm{MeOH}$, RT, overnight, 91\%; b) $\mathrm{MeONa} 0.1 \mathrm{M}, \mathrm{MeOH}, 0^{\circ} \mathrm{C}$ then $5^{\circ} \mathrm{C}, 1 \mathrm{~h}$; c) $\mathrm{TBDMS}-\mathrm{Cl}$, $\mathrm{AgNO}_{3}$, pyridine, DMF, RT, $15 \mathrm{~h}, 67 \%$ over two steps; d) $\mathrm{MeONa}, \mathrm{MeOH}, 40^{\circ} \mathrm{C}, 15 \mathrm{~h}, 96 \%$; e) 1 . $\mathrm{NaH}, \mathrm{Et}_{2} \mathrm{O}, 0^{\circ} \mathrm{C}, 0.5 \mathrm{~h} ; 2$. ethyl (S)-2-trifluoromethylsulfonyloxy)propionate, $0^{\circ} \mathrm{C}$ to $\mathrm{RT}$, overnight, 49\%; f) $\mathrm{HBF}_{4}, \mathrm{ACN}, 2 \mathrm{~h}, \mathrm{RT}, 60 \%$; g) 1. LiOH, THF, dioxane, $\mathrm{H}_{2} \mathrm{O}, 3 \mathrm{~h}, \mathrm{RT}$; 2. 
Peptide 7, EDC, HOAt, DMF then DIPEA, 0.5h, $0^{\circ} \mathrm{C} ; 3$. Piperidine, DMF, 8h, RT; 4. LiOH, THF, dioxane, $\mathrm{H}_{2} \mathrm{O}, 7.5 \mathrm{~h}, \mathrm{RT}, 65 \%$ over 4 steps.

Silver nitrate was used as co-reagent to ensure complete silylation of $2 .^{[13]}$ After deprotection of the remaining acetyl group, 4 was alkylated with $(S)$-propionic ethyl ester triflate and $\mathrm{NaH}$ in diethyl ether to introduce the lactyl group following Paulsen's procedure. ${ }^{[14]}$ The yield of alkylation $(49 \%)$ was modest but in agreement with previous studies reporting similar reactions. ${ }^{[8,14]}$ Attempts to improve the formation of $\mathbf{5}$ remained unsuccessful. We observed the concomitant $N$-alkylation of acetamido groups when a larger quantity of triflate was involved. Running the reaction in DCM or THF did not give better yields. The use of bromopropionic acid as an alternative alkylating agent gave poor results in our hands. Finally, NMR characterization of $\mathbf{5}$ confirmed that no racemization occurred during the alkylation step. At this stage of the synthesis, the herein developed approach compares favorably with the expedient route described by Marques et al.. ${ }^{[8]}$ Starting from di$N$-TFA-S-tolyl $\beta$-chitobioside they obtained a fully protected NAG-NAM disaccharide in four steps with an overall yield of $7 \%$. In this study, starting from $O$-benzyl $\beta$-chitinbioside, NAGNAM derivative 5 was obtained with an overall yield of $31 \%$ with the same number of steps. Deprotection of the silyl groups with fluoroboric acid in ACN afforded benzyl $\beta$-NAG-NAM ethyl ester 6 in $60 \%$ yield with excellent purity after purification by silica gel flash-column chromatography. L-Ala-D-iso-Glu-L-Lys-D-Ala-D-Ala is a PG constitutive pentapeptide found in multi-drug resistant bacteria such as Staphylococcus aureus, Enterococcus faecalis and Pseudomonas aeruginosa strains. ${ }^{[15]}$ The preparation of PG oligomers containing this peptide stem would be very valuable. After a step of saponification, $\mathbf{6}$ could be coupled with 
H-L-Ala-D-iso-Glu(OMe)-L-Lys(Fmoc)-D-Ala-D-Ala-OMe $\quad 7 \quad$ TFA salt, giving the disaccharide benzyl $\beta$-NAG-NAM pentapeptide $\mathbf{8}$ in $65 \%$ yield.

Compounds $\mathbf{6}$ and $\mathbf{8}$ constitute ideal building blocks for an enzymatic-based synthesis of PG oligomers. Selective deprotection of the benzyl protecting group and further activation of the anomeric position either as a glycosyl fluoride or as an oxazoline could indeed provide suitable donor for a glycosynthase while $\mathbf{6}$ or $\mathbf{8}$ would be used as acceptors. To this purpose we are developing lysozyme glycosynthase mutants of hen egg white lysozyme (HEWL).

\section{Acknowledgements}

This work was supported by the French National Research Agency (ANR) through Glyco_Swim (ANR-20-CE07-0012-01), Labex ARCANE, Glyco@Alps (ANR-15-IDEX-02). The NanoBio ICMG (UAR 2607) is acknowledged for providing facilities for mass spectrometry (A. Durand, L. Fort, R. Gueret) and NMR analyses (I. Jeacomine).

\section{Conflict of Interest}

The authors declare no conflict of interest.

[1] a) P. Sarkar, V. Yarlagadda, C. Ghosh, J. Haldar, MedChemComm 2017, 8, 516-533; b)

D. A. Dik, J. F. Fisher, S. Mobashery, Chem. Rev. 2018, 118, 5952-5984.

[2] M. McKenna, Nature 2013, 499, 394-396.

[3] R. S. Rosenthal, R. S. Dziarski, Methods Enzymol. 1994, 235, 253-285.

[4] K. Schaefer, T. W. Owens, D. Kahne, S. Walker, J. Am. Chem. Soc. 2018, 140, 24422445. 
[5] F. Queda, G. Covas, T. Silva, C. Almeida Santos, M. R. Bronze, F. J. Canada, M. C. Corvo, S. R. Filipe, M. M. B. Marques, Carbohydr. Polym. 2019, 224, 115133.

[6] a) D. Hesek, M. Lee, K.-I. Morio, S. Mobashery, J. Org. Chem. 2004, 69, 2137-2146; b) S. Inamura, Y. Fujimoto, A. Kawasaki, Z. Shiokawa, E. Woelk, H. Heine, B. Lindner, N. Inohara, S. Kusumoto, K. Fukase, Org. Biomol. Chem. 2006, 4, 232-242; c) N. Wang, H. Hasegawa, C.-Y. Huang, K. Fukase, Y. Fujimoto, Chem. Asian J. 2017, 12, 27-30.

[7] M. R. Hayes, J. Pietruszka, Molecules 2017, 22, 1434-1454.

[8] L. C. R. Carvalho, F. Queda, C. V. Almeida, S. R. Filipe, M. M. B. Marques, Asian J. Org. Chem. 2018, 7, 2544-2551.

[9] S. V. Ley, A. Polara, J. Org. Chem. 2007, 72, 5943-5959.

[10] M. Filice, J. M. Guisan, M. Terreni, J. M. Palomo, Nat. Protoc. 2012, 7, 1783-1795.

[11] a) B. A. Dmitriev, A. V. Nikolaev, A. S. Shashkov, N. K. Kochetkov, Carbohydr. Res. 1982, 100, 195-206; b) Z. Szurmai, A. Liptak, Carbohydr. Res. 1990, 200, 200-1-208; c) E. Petrakova, C. P. J. Glaudemans, Carbohydr. Res. 1995, 268, 135-141; d) K. Agoston, A. Dobo, J. Rako, J. Kerekgyarto, Z. Szurmai, Carbohydr. Res. 2001, 330, 183-190.

[12] D. R. Bundle, H. J. Jennings, I. C. P. Smith, Can. J. Chem. 1973, 51, 3812- 3819.

[13] G. H. Hakimelahi, Z. A. Proba, K. K. Ogilvie, Can. J. Chem. 1982, 60, 1106- 1113.

[14] a) H. Paulsen, P. Himpkamp, T. Peters, Liebigs Ann. Chem. 1986, 664-674; b) W. Kinzy, R. R. Schmidt, Liebigs Ann. Chem. 1987, 407-415. 
[15] J.-X. He, K. Le Mai Hoang, S. H. Kho, Z. Guo, W. Zhong, K. R. V. Thappeta, R. Zamudio-Vázquez, S. N. Hoo, Q. Xiong, H. Duan, L. Yang, M. B. Chan-Park, X.-W. Liu, Chem. Sci. 2020, 11, 3171-3179. 


\section{Supporting Information}

\section{Content:}

I. General

II. Preparation of compounds 1-8

III. References

IV. ${ }^{1} \mathrm{H}$ and ${ }^{13} \mathrm{C}$ NMR spectra of compounds $\mathbf{1 - 8}$

\section{General}

Chitinbiose used in this work was produced through the cell factory technology from recombinant Escherichia coli. ${ }^{[1]}$ Chemicals were purchased from Sigma-Aldrich (SaintQuentin-Fallavier, France) or TCI (Europe) and used directly without further purification. NMR spectra were recorded in $\mathrm{D}_{2} \mathrm{O}$, THF- $d_{8}$, DMSO- $d_{6}$, or MeOD with a liquid Bruker Avance III $400 \mathrm{MHz}$ spectrometer $\left({ }^{1} \mathrm{H}: 400 \mathrm{MHz},{ }^{13} \mathrm{C}: 100 \mathrm{MHz}\right)$. The solvent residual peaks of $\mathrm{D}_{2} \mathrm{O}, \mathrm{THF}-d_{8}, \mathrm{DMSO}-d_{6}$ or MeOD were used as internal standards at $4.80 \mathrm{ppm}$ for $\mathrm{D}_{2} \mathrm{O}$, 3.58 and $1.73 \mathrm{ppm}$ for THF- $d_{8}, 3.31$ for MeOD and $2.51 \mathrm{ppm}$ for DMSO- $d_{6}$ for ${ }^{1} \mathrm{H}$ NMR, 25.37 and $67.57 \mathrm{ppm}$ for THF- $d_{8}, 49.1$ for MeOD and $39.51 \mathrm{ppm}$ for DMSO- $d_{6}$ for ${ }^{13} \mathrm{C} \mathrm{NMR}$ (298 K). Chemical shifts $\delta$ are reported in ppm relative to the solvent residual peak. Coupling constants $\mathbf{J}$ are expressed in Hz. Multiplicity is designated by s (singulet), d (doublet), $\mathrm{t}$ (triplet), m (multiplet). Reactions were monitored by TLC (Merck Silica gel 60F254). Detection was achieved by dipping into a $30 \%$ ammonium sulfate solution in $\mathrm{H}_{2} \mathrm{O}$ followed by heating with a heat gun. Purifications were performed by flash-column chromatography (wet-packed silica, Merck 0.04-0.063 mm) or size-exclusion chromatography (SEC). SEC was performed with three Hiload Superdex 30 columns (10-300GL) in series using refractive index detection. Elution was performed with $0.1 \mathrm{M}$ carbonate ammonium at a flow rate of 1.2 $\mathrm{mL} / \mathrm{min}$. Mass analyses (ESI) were recorded with an ESQUIRE 3000+ (Bruker Daltonics) and HRMS spectra were recorded with a LTQ-Orbitrap XL (Thermo Scientific). 


\section{Preparation of compounds 1-9}

II.1 Benzyl $O$-(2-acetamido-2-deoxy- $\beta$-D-glucopyranosyl)-(1 $\rightarrow 4)-2$-acetamido-2-deoxy- $\beta$ D-glucopyranoside $\underline{1}$

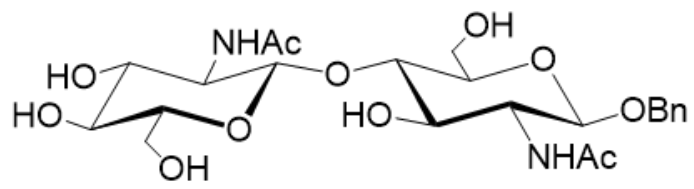

Sodium methoxide (1.8 $\mathrm{mL}, 1 \mathrm{M}$ in $\mathrm{MeOH})$ was added dropwise to a solution of benzyl $\beta$ chitinbioside pentaacetate $^{2,3}(1.783 \mathrm{~g}, 2.46 \mathrm{mmol})$ in [MeOH-DCM (6:1), $105 \mathrm{~mL}$ ]. The solution was stirred overnight and then neutralized with strong acid cation-exchange resin (Amberlite ${ }^{\circledR} \mathrm{IRN}-77 \mathrm{H}^{+}$form). After filtration and concentration under reduced pressure, benzyl chitinbioside 1 was freeze dried $(1.145 \mathrm{~g}, 91 \%), \delta_{\mathrm{H}}\left[\mathrm{D}_{2} \mathrm{O}\right] 1.94\left(3 \mathrm{H}, \mathrm{s}, \mathrm{NHCOCH}_{3}{ }^{\mathrm{I}}\right)$, $2.09\left(3 \mathrm{H}, \mathrm{s}, \mathrm{NHCOCH}_{3}{ }^{\mathrm{II}}\right), 3.48\left(1 \mathrm{H}, \mathrm{H}-4^{\mathrm{II}}\right), 3.50\left(2 \mathrm{H}, \mathrm{H}-5^{\mathrm{I}}\right.$ and $\left.\mathrm{H}-5^{\mathrm{II}}\right), 3.57\left(1 \mathrm{H}, \mathrm{H}-3^{\mathrm{II}}\right)$, $3.61\left(1 \mathrm{H}, \mathrm{H}-4^{\mathrm{I}}\right), 3.64\left(1 \mathrm{H}, \mathrm{H}-3^{\mathrm{I}}\right), 3.69$ and $3.89\left(2 \mathrm{H}, \mathrm{H}-6 \mathrm{a} \mathrm{b}^{\mathrm{I}}\right), 3.75\left(1 \mathrm{H}, \mathrm{dd}, \mathrm{H}-2^{\mathrm{I}}\right), 3.75-$ $3.90\left(2 \mathrm{H}, \mathrm{H}-6 \mathrm{a} 6 \mathrm{~b}^{\mathrm{II}}\right), 3.76\left(1 \mathrm{H}, \mathrm{H}-2^{\mathrm{II}}\right), 4.54\left(1 \mathrm{H}, \mathrm{d}, J_{1,2}=8.3, \mathrm{H}-1^{\mathrm{II}}\right), 4.59\left(1 \mathrm{H}, \mathrm{d}, J_{1,2}=8.4\right.$, $\left.\mathrm{H}-1^{\mathrm{I}}\right), 4.67$ and $4.89\left(2 \mathrm{H}, \mathrm{d}, J_{\mathrm{H}, \mathrm{H}}=12.1 \mathrm{OCH}_{2} \mathrm{Ph}\right), 7.37$ to $7.49(5 \mathrm{H}, \mathrm{Ph}) ; \delta_{\mathrm{C}}\left[\mathrm{D}_{2} \mathrm{O}\right] 22.1$ $\left(\mathrm{NHCOCH}_{3}{ }^{\mathrm{I}}\right.$ and $\left(\mathrm{NHCOCH}_{3}{ }^{\mathrm{II}}\right), 54.0\left(\mathrm{C}-2^{\mathrm{I}}\right), 55.6\left(\mathrm{C}-2^{\mathrm{II}}\right), 60.1\left(\mathrm{C}-6^{\mathrm{I}}\right), 60.5\left(\mathrm{C}-6^{\mathrm{II}}\right), 69.7(\mathrm{C}-$ $\left.4^{\mathrm{II}}\right), 71.5\left(\mathrm{OCH} \mathrm{H}_{2} \mathrm{Ph}\right), 73.5\left(\mathrm{C}-3^{\mathrm{II}}\right), 72.3\left(\mathrm{C}-3^{\mathrm{I}}\right), 74.5\left(\mathrm{C}-5^{\mathrm{I}}\right), 79.5\left(\mathrm{C}-4^{\mathrm{I}}\right), 75.8\left(\mathrm{C}-5^{\mathrm{II}}\right), 99.8(\mathrm{C}-$ $\left.1^{\mathrm{I}}\right), \quad 101.4\left(\mathrm{C}-1^{\mathrm{II}}\right), \quad 128.4,128.5,128.7$ and $136.7(\mathrm{Ph}), 174.4\left(\mathrm{NHCOCH}_{3}{ }^{\mathrm{I}}\right), 174.6$ $\left(\mathrm{NHCOCH}_{3}{ }^{\mathrm{II}}\right)$.

II.2 Benzyl $O$-(2-acetamido-2-deoxy- $\beta$-D-glucopyranosyl)-(1 $\rightarrow 4)$-2-acetamido-3- $O$-acetyl2-deoxy- $\beta$-D-glucopyranoside $\underline{2}$

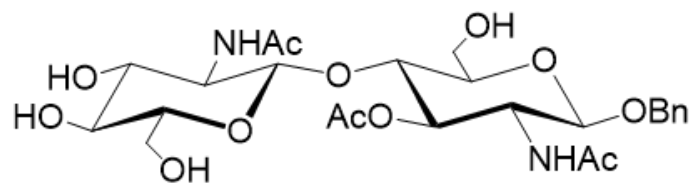

Sodium methoxide $(0.56 \mathrm{ml}, 1 \mathrm{M}$ in $\mathrm{MeOH})$ was added dropwise to an ice-cooled solution of benzyl $\beta$-chitinbioside pentaacetate ${ }^{[2,3]}(575 \mathrm{mg}, 0.79 \mathrm{mmol})$ in $\mathrm{MeOH}(56 \mathrm{~mL})$. The temperature was raised to $5^{\circ} \mathrm{C}$, and after stirring for $1 \mathrm{~h}$ the solution was neutralized with 
strong acid cation-exchange resin (Amberlite ${ }^{\circledR}$ IRN-77 $\mathrm{H}^{+}$form). After filtration and concentration under reduced pressure, the crude product was used without further purification in the next step. An aliquot could be purified by flash-column chromatography $\left[\mathrm{ACN}-\mathrm{H}_{2} \mathrm{O}\right.$ $(9: 1)]$ to give pure benzyl chitinbioside hexaacetate 2 for characterization; HRMS (positive ionisation mode) $\mathrm{m} / \mathrm{z}$ 557.23238, corresponding to $\mathrm{C}_{25} \mathrm{H}_{37} \mathrm{~N}_{2} \mathrm{O}_{12}[\mathrm{M}+\mathrm{H}]^{+}$(requires $\mathrm{m} / \mathrm{z}$ 557.23410); $\delta_{\mathrm{H}}\left[\mathrm{D}_{2} \mathrm{O}\right] 1.92\left(3 \mathrm{H}, \mathrm{s}, \mathrm{NHCOCH}_{3}{ }^{\mathrm{I}}\right), 2.11\left(3 \mathrm{H}, \mathrm{s}, \mathrm{NHCOCH}_{3}{ }^{\mathrm{II}}\right), 2.15(3 \mathrm{H}, \mathrm{s}$, $\left.\mathrm{OCOCH}_{3}\right), 3.42\left(1 \mathrm{H}, \mathrm{H}-5^{\mathrm{II}}\right), 3.47\left(1 \mathrm{H}, \mathrm{H}-4^{\mathrm{II}}\right), 3.55\left(1 \mathrm{H}, \mathrm{H}-3^{\mathrm{II}}\right), 3.60\left(1 \mathrm{H}, \mathrm{H}-5^{\mathrm{I}}\right), 3.65(1 \mathrm{H}$, $\left.\mathrm{H}-2^{\mathrm{II}}\right), 3.79$ and $3.88\left(2 \mathrm{H}, \mathrm{H}-6 \mathrm{a} 6 \mathrm{~b}^{\mathrm{II}}\right), 3.90\left(1 \mathrm{H}, \mathrm{dd}, \mathrm{H}-2^{\mathrm{I}}\right), 3.91\left(1 \mathrm{H}, \mathrm{H}-4^{\mathrm{I}}\right), 3.74$ and $3.94(2$ $\left.\mathrm{H}, \mathrm{H}-6 \mathrm{a} 6 \mathrm{~b}^{\mathrm{I}}\right), 4.56\left(1 \mathrm{H}, \mathrm{d}, J_{1,2}=8.2, \mathrm{H}^{\mathrm{II}}\right), 4.72\left(1 \mathrm{H}, \mathrm{d}, J_{1,2}=8.6, \mathrm{H}-1^{\mathrm{I}}\right), 4.72$ and $4.93(2 \mathrm{H}$, $\left.\mathrm{d}, J_{\mathrm{H}, \mathrm{H}}=12.0 \mathrm{OCH}_{2} \mathrm{Ph}\right), 5.08\left(1 \mathrm{H}, \mathrm{q}, \mathrm{H}-3^{\mathrm{I}}\right), 7.40$ to $7.51(5 \mathrm{H}, \mathrm{Ph}) ; \delta_{\mathrm{C}}\left[\mathrm{D}_{2} \mathrm{O}\right] 20.4$ $(\mathrm{OCOCH} 3), 21.8\left(\mathrm{NHCOCH}_{3}{ }^{\mathrm{I}}\right), 22.2\left(\mathrm{NHCOCH}_{3}{ }^{\mathrm{II}}\right), 53.9\left(\mathrm{C}-2^{\mathrm{I}}\right), 55.9\left(\mathrm{C}-2^{\mathrm{II}}\right), 60.0\left(\mathrm{C}-6^{\mathrm{I}}\right)$, $60.5\left(\mathrm{C}-6^{\mathrm{II}}\right), 69.6\left(\mathrm{C}-4^{\mathrm{II}}\right), 71.6\left(\mathrm{OCH}_{2} \mathrm{Ph}\right), 73.5\left(\mathrm{C}-3^{\mathrm{II}}\right), 74.1\left(\mathrm{C}-3^{\mathrm{I}}\right), 74.8\left(\mathrm{C}-5^{\mathrm{I}}\right), 75.8\left(\mathrm{C}-4^{\mathrm{I}}, \mathrm{C}-\right.$ $\left.5^{\mathrm{II}}\right), 99.1\left(\mathrm{C}-1^{\mathrm{I}}\right), 101.4\left(\mathrm{C}-1^{\mathrm{II}}\right), 128.6$ to 128.8 and $136.5(\mathrm{Ph}), 173.3\left(\mathrm{COCH}_{3}\right), 174.3$ $\left(\mathrm{NHCOCH}_{3}{ }^{\mathrm{I}}\right), 174.6\left(\mathrm{NHCOCH}_{3}{ }^{\mathrm{II}}\right)$.

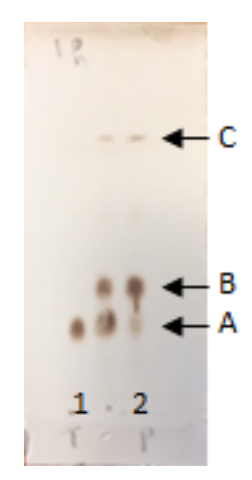

Thin-layer chromatography of crude mono- $O$-acetate 2 [ACN- $\left.\mathrm{H}_{2} \mathrm{O}(9: 1)\right]$.

Lane 1 and A: $\beta$-benzyl chitinbioside 1

Lane 2: crude product

B: mono- $O$-acetate 2

C: residual starting $\beta$-benzyl chitinbioside pentaacetate

II.3 Benzyl $O$-(2-acetamido-3,4,6-tri- $O$-tert-butyldimethylsilyl-2-deoxy- $\beta$-Dglucopyranosyl)-( $1 \rightarrow 4)$-2-acetamido-3- $O$-acetyl-2-deoxy- $\beta$-D-glucopyranoside $\underline{3}$

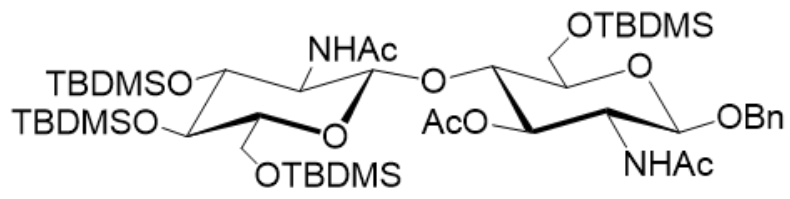

Crude 2 obtained from selective de- $O$-acetylation of benzyl- $\beta$-chitinbioside pentaacetate (575 mg, $0.79 \mathrm{mmol}$ ) was co-evaporated two times with toluene, then dissolved in dry DMF $(15 \mathrm{~mL})$, and added of dry pyridine $(2.6 \mathrm{~mL}, 32.3 \mathrm{mmol}, 10$ equiv/OH), followed by silver 
nitrate (1.65 g, $9.6 \mathrm{mmol}, 3$ equiv/OH). Silver nitrate was solubilized with the help of an ultrasonic bath, and tert-butyldimethylsilylchloride (1.46 g, 9,5 mmol, 3 equiv/OH) was added and the solution was stirred for $15 \mathrm{~h}$ at room temperature, protected from light. After filtration over a bed of celite and washing with $\mathrm{MeOH}$, the solution was concentrated under reduced pressure and purified by flash chromatography [first toluene then toluene-acetone (9-1)] to give the mono- $O$-acetate 3 (539 mg, 67\%), HRMS (positive ionisation mode) $\mathrm{m} / \mathrm{z}$ 1013.57932, corresponding to $\mathrm{C}_{49} \mathrm{H}_{93} \mathrm{~N}_{2} \mathrm{O}_{12} \mathrm{Si}_{4}[\mathrm{M}+\mathrm{H}]^{+}$(requires $\mathrm{m} / \mathrm{z} 1013.58001$ ); ), $\delta_{\mathrm{H}}$ [THF- $d_{8}$ ] 0.09 to $0.20\left(24 \mathrm{H}, 8 \mathrm{~s}, \mathrm{Si}\left(\mathrm{CH}_{3}\right)_{2}\right), 0.90$ to $0.94\left(36 \mathrm{H}, \mathrm{SiC}\left(\mathrm{CH}_{3}\right)_{3}\right), 1.76(3 \mathrm{H}, \mathrm{s}$, $\left.\mathrm{NHCOCH}_{3}{ }^{\mathrm{I}}\right), 1.84\left(3 \mathrm{H}, \mathrm{s}, \mathrm{NHCOCH}_{3}{ }^{\mathrm{II}}\right), 1.92\left(3 \mathrm{H}, \mathrm{s}, \mathrm{COCH}_{3}\right), 3.37\left(1 \mathrm{H}, \mathrm{H}-5^{\mathrm{I}}\right), 3.65(1 \mathrm{H}$, H-5 $\left.{ }^{\mathrm{II}}\right), 3.72$ and $4.03\left(2 \mathrm{H}, \mathrm{H}-6 \mathrm{abb}^{\mathrm{II}}\right), 3.74\left(1 \mathrm{H}, \mathrm{H}-4^{\mathrm{I}}\right), 3.85\left(1 \mathrm{H}, \mathrm{H}-3^{\mathrm{II}}\right), 3.88\left(1 \mathrm{H}, \mathrm{H}-2^{\mathrm{II}}\right)$, 3.88 and $3.99\left(2 \mathrm{H}, \mathrm{H}-6 \mathrm{abb}^{\mathrm{I}}\right), 3.93\left(1 \mathrm{H}, \mathrm{H}-2^{\mathrm{I}}\right), 3.96\left(1 \mathrm{H}, \mathrm{H}-4^{\mathrm{II}}\right), 4.54\left(1 \mathrm{H}, \mathrm{d}, J_{1,2}=8.4, \mathrm{H}-\right.$ $\left.1^{\mathrm{I}}\right), 4.57$ and $4.81\left(2 \mathrm{H}, \mathrm{d}, J_{\mathrm{H}, \mathrm{H}}=12.2, \mathrm{CH}_{2} \mathrm{Ph}\right), 4.65\left(1 \mathrm{H}, \mathrm{d}, J_{1,2}=4.4, \mathrm{H}-1^{\mathrm{II}}\right), 5.02(1 \mathrm{H}, \mathrm{dd}$, $\left.J_{2,3}=J_{3,4}=9.4, \mathrm{H}^{-} 3^{\mathrm{I}}\right), 6.44\left(1 \mathrm{H}, \mathrm{d}, \mathrm{NH}^{\mathrm{II}}\right), 6.98\left(1 \mathrm{H}, \mathrm{d}, \mathrm{NH}^{\mathrm{II}}\right), 7.20$ to $7.25(5 \mathrm{H}, \mathrm{Ph}) ; \delta_{\mathrm{C}}$ $\left[\mathrm{THF}_{8}\right]-5.0$ to $-3.9\left(\mathrm{Si}\left(\mathrm{CH}_{3}\right)_{2}\right), 18.9$ to $19.3\left(\mathrm{Si} \mathrm{SiC}\left(\mathrm{CH}_{3}\right)_{3}\right), 21.4\left(\mathrm{COCH}_{3}\right), 23.1$ $\left(\mathrm{NHCOCH}_{3}{ }^{\mathrm{I}}\right), 23.4\left(\mathrm{NHCOCH}_{3}{ }^{\mathrm{II}}\right), 26.7\left(\mathrm{SiC}\left(\mathrm{CH}_{3}\right)_{3}\right), 54.7\left(\mathrm{C}-2^{\mathrm{I}}\right), 55.2\left(\mathrm{C}-2^{\mathrm{II}}\right), 63.5\left(\mathrm{C}-6^{\mathrm{I}}\right)$, $64.7\left(\mathrm{C}-6^{\mathrm{II}}\right), 70.5\left(\mathrm{OCH}_{2} \mathrm{Ph}\right), 70.7\left(\mathrm{C}^{-4^{\mathrm{II}}}\right), 74.4\left(\mathrm{C}-3^{\mathrm{II}}\right), 75.2\left(\mathrm{C}-3^{\mathrm{I}}\right), 76.8\left(\mathrm{C}-5^{\mathrm{I}}\right), 77.8\left(\mathrm{C}-4^{\mathrm{I}}\right)$,

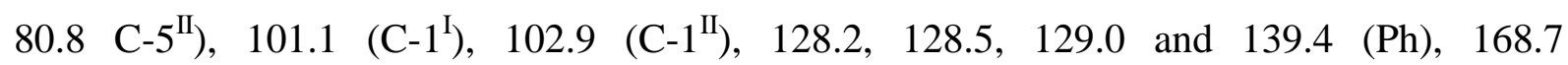
$\left(\mathrm{NHCOCH}_{3}{ }^{\mathrm{II}}\right), 169.6\left(\mathrm{NHCOCH}_{3}{ }^{\mathrm{I}}\right), 170.8\left(\mathrm{COCH}_{3}\right)$.

\section{II.4 Benzyl $O$-(2-acetamido-3,4,6-tri- $O$-tert-butyldimethylsilyl-2-deoxy- $\beta$-D- glucopyranosyl)-(1 $\rightarrow 4)$-2-acetamido-6- $O$-tert-butyldimethylsilyl-2-deoxy- $\beta$-D- glucopyranoside $\underline{4}$}

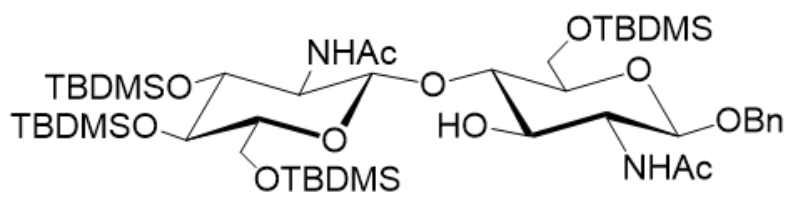

Sodium methoxide $(0.03 \mathrm{~mL}, 1 \mathrm{M}$ in $\mathrm{MeOH})$ was added dropwise to a solution of benzyl$\beta$-chitinbioside mono- $O$-acetate $2(121 \mathrm{mg}, 0.119 \mathrm{mmol})$ in $\mathrm{MeOH}(3 \mathrm{~mL})$. The temperature was raised to $40^{\circ} \mathrm{C}$, and after $15 \mathrm{~h}$ the solution was neutralized with strong acid cationexchange resin (Amberlite ${ }^{\circledR}$ IRN-77 $\mathrm{H}^{+}$form). Compounds 3 and 4 having the same $\mathrm{Rf}$ on 
TLC [cyclohexane-diethyl ether (1:1) or toluene-acetone (3:1)], completion of the reaction was checked by ESI MS (positive ionization mode), m/z $972[\mathrm{M}+\mathrm{H}]^{+}, 1014[\mathrm{M}+\mathrm{Na}]^{+}$. After filtration and concentration under reduced pressure, the resulting mixture was percolated through a short column of silica gel with diethyl ether as the eluent and concentrated under reduced pressure to give $4(111 \mathrm{mg}, 96 \%) . \delta_{\mathrm{H}}\left[\mathrm{THF}-d_{8}\right] 0.09$ to $0.20\left(24 \mathrm{H}, 8 \mathrm{~s}, \mathrm{Si}\left(\mathrm{CH}_{3}\right)_{2}\right)$, 0.88 to $0.94\left(36 \mathrm{H}, \mathrm{SiC}\left(\mathrm{CH}_{3}\right)_{3}\right), 1.81\left(3 \mathrm{H}, \mathrm{s}, \mathrm{NHCOCH}_{3}{ }^{\mathrm{I}}\right), 1.87\left(3 \mathrm{H}, \mathrm{s}, \mathrm{NHCOCH}_{3}{ }^{\mathrm{II}}\right), 3.32$ $\left(1 \mathrm{H}, \mathrm{H}-5^{\mathrm{I}}\right), 3.41\left(1 \mathrm{H}, \mathrm{H}-5^{\mathrm{II}}\right), 3.42\left(1 \mathrm{H}, \mathrm{H}-2^{\mathrm{I}}\right), 3.71\left(1 \mathrm{H}, \mathrm{H}-4^{\mathrm{I}}\right), 3.76\left(1 \mathrm{H}, \mathrm{H}-4^{\mathrm{II}}\right), 3.79(1 \mathrm{H}$, H-3 $\left.{ }^{\mathrm{I}}\right), 3.83$ and $3.94\left(2 \mathrm{H}, \mathrm{H}-6 \mathrm{a} 6 \mathrm{~b}^{\mathrm{II}}\right), 3.84\left(1 \mathrm{H}, \mathrm{H}-3^{\mathrm{II}}\right), 3.85$ and $3.93\left(2 \mathrm{H}, \mathrm{H}-6 \mathrm{abb}^{\mathrm{I}}\right), 3.92(1$ $\left.\mathrm{H}, \mathrm{H}-2^{\mathrm{II}}\right), 4.00$ and $4.83\left(2 \mathrm{H}, \mathrm{d}, J_{\mathrm{H}, \mathrm{H}}=12.2, \mathrm{CH}_{2} \mathrm{Ph}\right), 4.66\left(1 \mathrm{H}, \mathrm{d}, J_{1,2}=6.1, \mathrm{H}-1^{\mathrm{II}}\right), 4.69(1$ $\left.\mathrm{H}, \mathrm{d}, J_{1,2}=8.3, \mathrm{H}-1^{\mathrm{I}}\right), 6.54\left(1 \mathrm{H}, \mathrm{d}, \mathrm{NH}^{\mathrm{II}}\right), 7.00\left(1 \mathrm{H}, \mathrm{d}, \mathrm{NH}^{\mathrm{I}}\right), 7.20$ to $7.28(5 \mathrm{H}, \mathrm{Ph}) ; \delta_{\mathrm{C}}$ $\left[\mathrm{THF} d_{8}\right]-5.1$ to $-3.3\left(\mathrm{Si}\left(\mathrm{CH}_{3}\right)_{2}\right), 19.0$ to $19.2\left(\mathrm{SiC}\left(\mathrm{CH}_{3}\right)_{3}\right), 23.4\left(\mathrm{NHCOCH}_{3}{ }^{\mathrm{I}}\right), 23.6$ $\left(\mathrm{NHCOCH}_{3}{ }^{\mathrm{II}}\right), 26.7\left(\mathrm{SiC}\left(\mathrm{CH}_{3}\right)_{3}\right)\left(56.5\left(\mathrm{C}-2^{\mathrm{II}}\right), 57.4\left(\mathrm{C}-2^{\mathrm{I}}\right), 63.6\left(\mathrm{C}-6^{\mathrm{II}}\right), 65.3\left(\mathrm{C}-6^{\mathrm{I}}\right), 70.7\right.$

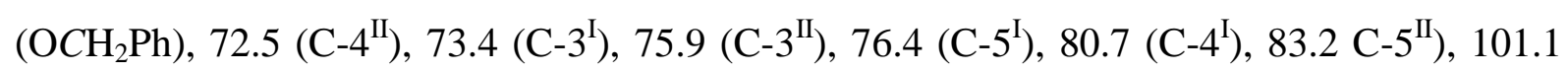
$\left(\mathrm{C}-1^{\mathrm{I}}\right), 102.9\left(\mathrm{C}-1^{\mathrm{II}}\right), 128.1,128.5,128.9$ and $139.7(\mathrm{Ph}), 169.0\left(\mathrm{NHCOCH}_{3}{ }^{\mathrm{II}}\right), 169.7$ $\left(\mathrm{NHCOCH}_{3}{ }^{\mathrm{I}}\right)$.

\section{II.5 Benzyl $O$-(2-acetamido-3,4,6-tri- $O$-tert-butyldimethylsilyl-2-deoxy- $\beta$-D-} glucopyranosyl)-(1 $\rightarrow 4)$-2-acetamido-6- $O$-tert-butyldimethylsilyl-2-deoxy-3-O-((R)-1'ethoxycarbonylethyl)- $\beta$-D-glucopyranoside $\underline{5}$

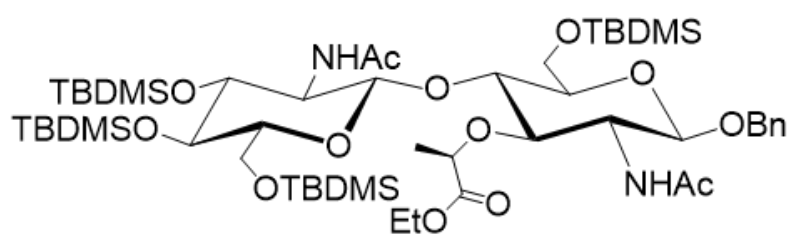

To an ice-cooled solution of mono-hydroxylated compound 4 (111 $\mathrm{mg}, 0.114 \mathrm{mmol})$ in dry diethyl ether $(12 \mathrm{~mL})$ was added $26 \mathrm{mg}$ of $\mathrm{NaH}$ (0.68 mmol, 5.7 equiv, $60 \%$ in oil), and the mixture was stirred for $0.5 \mathrm{~h}$ at $0^{\circ} \mathrm{C}$. (2S)-2-Trifluoromethylsulfonyloxy)propanoic acid ethylester $(0.081 \mathrm{~mL}, 0.36 \mathrm{mmol}, 3$ equiv) was added dropwise and the mixture was stirred from $0^{\circ} \mathrm{C}$ to room temperature overnight. Ice was added to decompose excess of sodium hydride, and the resulting solution was diluted with diethyl ether, washed successively with aq. $\mathrm{KHSO}_{4}$, aq. $\mathrm{NaHCO}_{3}$ and brine, dried $\left(\mathrm{Na}_{2} \mathrm{SO}_{4}\right)$, and concentrated under reduced pressure. 
Flash-column chromatography [cyclohexane-diethyl ether (1:1) then (1:2)] of the residue gave compound 5 (63 mg, 49\%), HRMS (positive ionisation mode) m/z 1071.62176, corresponding to $\mathrm{C}_{52} \mathrm{H}_{99} \mathrm{~N}_{2} \mathrm{O}_{13} \mathrm{Si}_{4}[\mathrm{M}+\mathrm{H}]^{+}$(requires $\mathrm{m} / \mathrm{z} 1071.62187$ ), $\delta_{\mathrm{H}}\left[\mathrm{THF}-d_{8}\right] 0.10$ to $0.20\left(24 \mathrm{H}, 8 \mathrm{~s}, \mathrm{Si}\left(\mathrm{CH}_{3}\right)_{2}\right), 0.92$ to $0.96\left(36 \mathrm{H}, \mathrm{SiC}\left(\mathrm{CH}_{3}\right)_{3}\right), 1.23\left(3 \mathrm{H}, \mathrm{t}, J_{\mathrm{H}, \mathrm{H}}=5.7, \mathrm{CH}_{2} \mathrm{CH}_{3}\right)$, $1.31\left(3 \mathrm{H}, \mathrm{d}, J_{\mathrm{H}, \mathrm{H}}=5.4, \mathrm{CHCH}_{3}\right), 1.85\left(3 \mathrm{H}, \mathrm{s}, \mathrm{NHCOCH}_{3}{ }^{\mathrm{II}}\right), 1.86\left(3 \mathrm{H}, \mathrm{s}, \mathrm{NHCOCH}_{3}{ }^{\mathrm{I}}\right), 3.32$ $\left(1 \mathrm{H}, \mathrm{H}-5^{\mathrm{I}}\right), 3.65\left(1 \mathrm{H}, \mathrm{H}-2^{\mathrm{I}}\right), 3.66\left(1 \mathrm{H}, \mathrm{H}-5^{\mathrm{II}}\right), 3.66\left(1 \mathrm{H}, \mathrm{H}-4^{\mathrm{I}}\right), 3.95\left(1 \mathrm{H}, \mathrm{H}-4^{\mathrm{II}}\right), 3.89(1 \mathrm{H}$, H-3 $\left.{ }^{\mathrm{I}}\right), 3.89\left(2 \mathrm{H}, \mathrm{H}^{-6 a 6 b^{\mathrm{II}}}\right), 3.84\left(1 \mathrm{H}, \mathrm{H}-3^{\mathrm{II}}\right), 3.81$ and $3.95\left(2 \mathrm{H}, \mathrm{H}-6 \mathrm{a} 6 \mathrm{~b}^{\mathrm{I}}\right), 3.95\left(1 \mathrm{H}, \mathrm{H}-2^{\mathrm{II}}\right)$, $4.10\left(2 \mathrm{H}, \mathrm{CH}_{2} \mathrm{CH}_{3}\right), 4.52$ and $4.84\left(2 \mathrm{H}, \mathrm{d}, J_{\mathrm{H}, \mathrm{H}}=9.7, \mathrm{CH}_{2} \mathrm{Ph}\right), 4.66\left(1 \mathrm{H}, \mathrm{d}, \mathrm{H}-1^{\mathrm{II}}\right), 4.67(1 \mathrm{H}$, q, $\left.\mathrm{CHCH}_{3}\right), 4.69\left(1 \mathrm{H}, \mathrm{d}, J_{1,2}=5.7, \mathrm{H}^{-1}{ }^{\mathrm{I}}\right), 6.25\left(1 \mathrm{H}, \mathrm{d}, \mathrm{NH}^{\mathrm{II}}\right), 7.03\left(1 \mathrm{H}, \mathrm{d}, \mathrm{NH}^{\mathrm{I}}\right), 7.18$ to $7.29(5 \mathrm{H}, \mathrm{Ph}) ; \delta_{\mathrm{C}}\left[\mathrm{THF} d_{8}\right]-5.9$ to $-4.4\left(\mathrm{Si}\left(\mathrm{CH}_{3}\right)_{2}\right), 13.6\left(\mathrm{CH}_{2} \mathrm{CH}_{3}\right), 17.9$ to $18.2\left(\mathrm{SiC}\left(\mathrm{CH}_{3}\right)_{3}\right)$, $18.4\left(\mathrm{CHCH}_{3}\right), 22.2\left(\mathrm{NHCOCH}_{3}{ }^{\mathrm{I}}\right), 22.3\left(\mathrm{NHCOCH}_{3}{ }^{\mathrm{II}}\right), 25.6$ to $25.7\left(\mathrm{SiC}\left(\mathrm{CH}_{3}\right)_{3}\right), 56.1\left(\mathrm{C}-2^{\mathrm{II}}\right)$, $54.2\left(\mathrm{C}-2^{\mathrm{I}}\right), 60.1\left(\mathrm{CH}_{2} \mathrm{CH}_{3}\right), 64.2\left(\mathrm{C}-6^{\mathrm{II}}\right), 61.8\left(\mathrm{C}-6^{\mathrm{I}}\right), 69.3\left(\mathrm{OCH}_{2} \mathrm{Ph}\right), 72.2\left(\mathrm{C}-4^{\mathrm{II}}\right), 74.4$ $\left.\left(\mathrm{CHCH}_{3}\right), 75.2\left(\mathrm{C}-3^{\mathrm{I}}\right), 75.9\left(\mathrm{C}-3^{\mathrm{II}}\right), 75.7\left(\mathrm{C}-5^{\mathrm{I}}\right), 77.8\left(\mathrm{C}-4^{\mathrm{I}}\right), 80.4 \mathrm{C}-5^{\mathrm{II}}\right), 100.7\left(\mathrm{C}-1^{\mathrm{I}}\right), 100.8$ $\left(\mathrm{C}-1^{\mathrm{II}}\right), 126.8,127.1,127.8$ and $138.7(\mathrm{Ph}), 167.9\left(\mathrm{NHCOCH}_{3}{ }^{\mathrm{II}}\right), 169.2\left(\mathrm{NHCOCH}_{3}{ }^{\mathrm{I}}\right), 174.1$ (CHCO).

II.6 Benzyl $O$-(2-acetamido-2-deoxy- $\beta$-D-glucopyranosyl)-(1 $\rightarrow 4)-2$-acetamido-2-deoxy-3$O$-((R)-1'-ethoxycarbonylethyl)- $\beta$-D-glucopyranoside $\underline{6}$

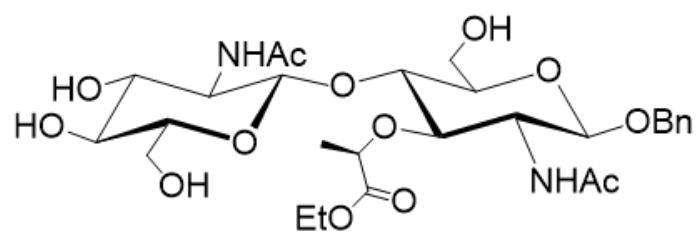

A solution of compound $5(169 \mathrm{mg}, 0.158 \mathrm{mmol})$ in acetonitrile $(15 \mathrm{~mL})$ containing tetrafluoroboric acid $\left(0.15 \mathrm{~mL}, 50 \%\right.$ in $\left.\mathrm{H}_{2} \mathrm{O}\right)$ was stirred at room temperature for $2 \mathrm{~h}$ and then neutralized with ammonia $\left(0.085 \mathrm{~mL}, 27 \%\right.$ in $\left.\mathrm{H}_{2} \mathrm{O}\right)$. The mixture was concentrated under reduced pressure. Flash-column chromatography [first ACN then $\mathrm{ACN}-\mathrm{H}_{2} \mathrm{O}$ (9:1)] of the residue followed by freeze drying gave the deprotected disaccharide 6 (58 mg, 60\%), HRMS (positive ionisation mode) $\mathrm{m} / \mathrm{z} 615.27502$, corresponding to $\mathrm{C}_{28} \mathrm{H}_{43} \mathrm{~N}_{2} \mathrm{O}_{13}[\mathrm{M}+\mathrm{H}]^{+}$(requires $\mathrm{m} / \mathrm{z} 615.27597), \delta_{\mathrm{H}}\left[\mathrm{D}_{2} \mathrm{O}\right] 1.28\left(3 \mathrm{H}, \mathrm{t}, J_{\mathrm{H}, \mathrm{H}}=7.2, \mathrm{CH}_{2} \mathrm{CH}_{3}\right), 1.44\left(3 \mathrm{H}, \mathrm{d}, J_{\mathrm{H}, \mathrm{H}}=6.8\right.$, $\left.\mathrm{CHCH}_{3}\right), 1.90$ and $2.04\left(2 \times 3 \mathrm{H}, \mathrm{s}, 2 \times \mathrm{NHCOCH}_{3}\right), 3.41\left(1 \mathrm{H}, \mathrm{H}-4^{\mathrm{II}}\right), 3.45\left(2 \mathrm{H}, \mathrm{H}-5^{\mathrm{I}}\right.$ and $\mathrm{H}-$ 
$\left.5^{\mathrm{II}}\right), 3.56\left(1 \mathrm{H}, \mathrm{H}-3^{\mathrm{II}}\right), 3.59\left(1 \mathrm{H}, \mathrm{H}-3^{\mathrm{I}}\right), 3.72\left(1 \mathrm{H}, \mathrm{H}-2^{\mathrm{II}}\right), 3.76\left(1 \mathrm{H}, \mathrm{H}-2^{\mathrm{I}}\right), 3.74$ and $3.94(2 \mathrm{H}$, $\left.\mathrm{H}-6 \mathrm{a} 6 \mathrm{~b}^{\mathrm{I}}\right), 3.76$ and $3.96\left(2 \mathrm{H}, \mathrm{H}-6 \mathrm{a} 6 \mathrm{~b}^{\mathrm{II}}\right), 4.20\left(2 \mathrm{H}, \mathrm{dq}, \mathrm{CH}_{2} \mathrm{CH}_{3}\right), 4.53\left(1 \mathrm{H}, \mathrm{d}, \mathrm{H}-1^{\mathrm{I}}\right), 4.53(1$ $\left.\mathrm{H}, \mathrm{d}, \mathrm{H}-1^{\mathrm{II}}\right), 4.54\left(1 \mathrm{H}, \mathrm{q}, \mathrm{CHCH}_{3}\right), 4.66$ and $4.89\left(2 \mathrm{H}, \mathrm{d}, J_{\mathrm{H}, \mathrm{H}}=12.2, \mathrm{CH}_{2} \mathrm{Ph}\right), 7.36$ to $7.49(5$ $\mathrm{H}, \mathrm{Ph}) ; \delta_{\mathrm{C}}\left[\mathrm{D}_{2} \mathrm{O}\right] 13.3\left(\mathrm{CH}_{2} \mathrm{CH}_{3}\right), 18.2\left(\mathrm{CHCH}_{3}\right), 22.0$ and $22.2\left(2 \mathrm{NHCOCH}_{3}\right), 54.9\left(\mathrm{C}-2^{\mathrm{I}}\right)$, $56.0\left(\mathrm{C}-2^{\mathrm{II}}\right), 60.0\left(\mathrm{C}-6^{\mathrm{I}}\right), 61.1\left(\mathrm{C}-6^{\mathrm{II}}\right), 62.2\left(\mathrm{CH}_{2} \mathrm{CH}_{3}\right), 70.3\left(\mathrm{C}-4^{\mathrm{II}}\right), 71.5\left(\mathrm{CH}_{2} \mathrm{Ph}\right), 73.5\left(\mathrm{C}-3^{\mathrm{II}}\right)$, $74.9\left(\mathrm{C}-4^{\mathrm{I}}\right), 75.1\left(\mathrm{C}-5^{\mathrm{I}}\right), 76.1\left(\mathrm{C}-5^{\mathrm{II}}\right), 77.3\left(\mathrm{CHCH}_{3}\right), 80.1\left(\mathrm{C}-3^{\mathrm{I}}\right), 99.8\left(\mathrm{C}-1^{\mathrm{I}}\right), 100.1\left(\mathrm{C}-1^{\mathrm{II}}\right)$, 128.4-136.6 (Ph), 174.0 and 174.6 (2 $\left.\mathrm{NHCOCH}_{3}\right), 175.2(\mathrm{CHCO})$.

\section{II.7 H-L-Ala-D-iso-Glu(OMe)-L-Lys(Fmoc)-D-Ala-D-Ala-OMe $\underline{7}$}

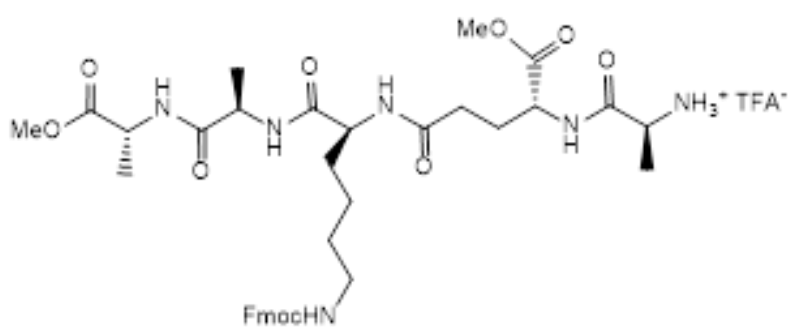

To a solution containing Boc-L-Ala-OSu (608 mg, $2.125 \mathrm{mmol}$ ) and H-D-GluOMe (342 $\mathrm{mg}, 2.125 \mathrm{mmol})$ in DMF (20 mL) was added saturated aq. $\mathrm{NaHCO}_{3}(4 \mathrm{~mL})$, and the resulting mixture was stirred overnight at room temperature. The solution was neutralized to $\mathrm{pH} 5$ with aq. $\mathrm{HCl}(1 \mathrm{M})$, diluted with $100 \mathrm{~mL}$ of $\mathrm{H}_{2} \mathrm{O}$, extracted three times with EtOAc, the organic layer washed with brine and then dried over $\mathrm{Na}_{2} \mathrm{SO}_{4}$ and concentrated under reduced pressure. Crude Boc-L-Ala-D-iso-Glu(OMe)-OH was added to a solution containing H-L-Lys(Fmoc)D-Ala-D-Ala-OMe.HCl (1.12 g, 2 mmol), ${ }^{[4]}$ DIPEA (1 mL, 5.75 mmol), HATU (1.52 g, 4 mmol) and HOAt (544 mg, $4 \mathrm{mmol})$ in DMF (40 mL). The resulting mixture was stirred overnight at room temperature, and then diluted with $\mathrm{H}_{2} \mathrm{O}(120 \mathrm{~mL})$. The precipitate was filtered over a bed of celite, washed with $\mathrm{H}_{2} \mathrm{O}$, dissolved in EtOAc, and concentrated under reduced pressure. Flash-column chromatography of the residue [first DCM then DCMacetone (4:1) then (3:2)] gave Boc-L-Ala-D-iso-Glu(OMe)-L-Lys(Fmoc)-D-Ala-D-Ala-OMe (423 mg, 25\%), HRMS (positive ionisation mode) $\mathrm{m} / \mathrm{z} 839.41666$, corresponding to $\mathrm{C}_{42} \mathrm{H}_{59} \mathrm{~N}_{6} \mathrm{O}_{12}[\mathrm{M}+\mathrm{H}]^{+}$(requires m/z 839.41855), $\delta_{\mathrm{H}}\left[\mathrm{DMSO}-d_{6}\right] 1.18(8 \mathrm{H}, \mathrm{t}, J=7.3), 1.29$ (4 $\mathrm{H}, \mathrm{d}, J=7.3), 1.36(12 \mathrm{H}, \mathrm{s}), 1.53(2 \mathrm{H}, \mathrm{m}), 1.86(2 \mathrm{H}, \mathrm{m}), 2.16(2 \mathrm{H}, \mathrm{m}), 2.94(2 \mathrm{H}, \mathrm{m}), 3.60$ $(6 \mathrm{H}, \mathrm{m}), 4.00(1 \mathrm{H}, \mathrm{t}, J=7.1), 4.13$ to $4.35(8 \mathrm{H}), 6.83(1 \mathrm{H}, \mathrm{d}, J=7.3), 7.24(1 \mathrm{H}, \mathrm{t}, J=5.4)$, 
$7.32(2 \mathrm{H}, \mathrm{t}, J=7.5), 7.41(2 \mathrm{H}, \mathrm{t}, J=7.3), 7.68(2 \mathrm{H}, \mathrm{d}, J=7.5), 7.88(2 \mathrm{H}, \mathrm{d}, J=7.6), 8.00$ $(1 \mathrm{H}, \mathrm{d}, J=6.9), 8.15$ to $8.18(3 \mathrm{H}) ; \delta_{\mathrm{C}}\left[\mathrm{DMSO}-d_{6}\right] 16.8,17.9,18.4,22.6,27.0,28.2,29.4$, 31.2, 31.4, 47.5, 47.6, 49.6, 51.4, 51.8, 53.0, 78.1, 109.8, 120.0, 121.4, 127.3, 128.9, 137.4, $139.4,142.6,155.0,157.2,171.5,172.1,172.8$.

An ice-cooled solution of Boc-L-Ala-D-iso-Glu(OMe)-L-Lys(Fmoc)-D-Ala-D-Ala-OMe (20 mg, $24 \mu \mathrm{mol})$ in TFA $(2 \mathrm{~mL})$ was stirred for $0.5 \mathrm{~h}$, and then was concentrated under reduced pressure and coevaporated three times with $\mathrm{H}_{2} \mathrm{O}$. The residue was washed three times with diethyl ether and dried under vacuum to give the TFA salt of H-L-Ala-D-iso-Glu(OMe)L-Lys(Fmoc)-D-Ala-D-Ala-OMe 7 (20 mg, 90\%), HRMS (positive ionisation mode) m/z 739.36428, corresponding to $\mathrm{C}_{37} \mathrm{H}_{51} \mathrm{~N}_{6} \mathrm{O}_{10}[\mathrm{M}+\mathrm{H}]^{+}$(requires $\mathrm{m} / \mathrm{z} 739.36612$ ), $\delta_{\mathrm{H}}[\mathrm{MeOD}]$ 1.35 to $1.70(14 \mathrm{H}), 1.76$ to $1.92(2 \mathrm{H}), 2.21$ to $2.33(3 \mathrm{H}), 3.11(1 \mathrm{H}, \mathrm{t}, J=6.8), 3.68$ to 3.71 $(6 \mathrm{H}), 4.17$ to $4.25(2 \mathrm{H}), 4.32$ to $4.50(5 \mathrm{H}), 7.30(2 \mathrm{H}, \mathrm{t}, J=7.4), 7.39(2 \mathrm{H}, \mathrm{t}, J=7.4), 7.64$ (2 H, d, $J=7.5), 7.79(2 \mathrm{H}, \mathrm{d}, J=7.6) ; \delta_{\mathrm{C}}[\mathrm{MeOD}] 17.2,17.9,18.1,24.1,28.3,30.6,32.2$, 32.3, 41.4, 48.6, 49.6, 50.0, 50.3, 52.8, 53.0, 53.1, 55.3, 67.7, 121.0, 126.2, 128.2, 128.8, $142.7,145.4,159.0,161.9,162.3,171.3,173.3,174.3,174.5,174.7,175.0$.

\section{II.8 Benzyl-O-GIcNAc-MurNAc pentapeptide $\underline{8}$}

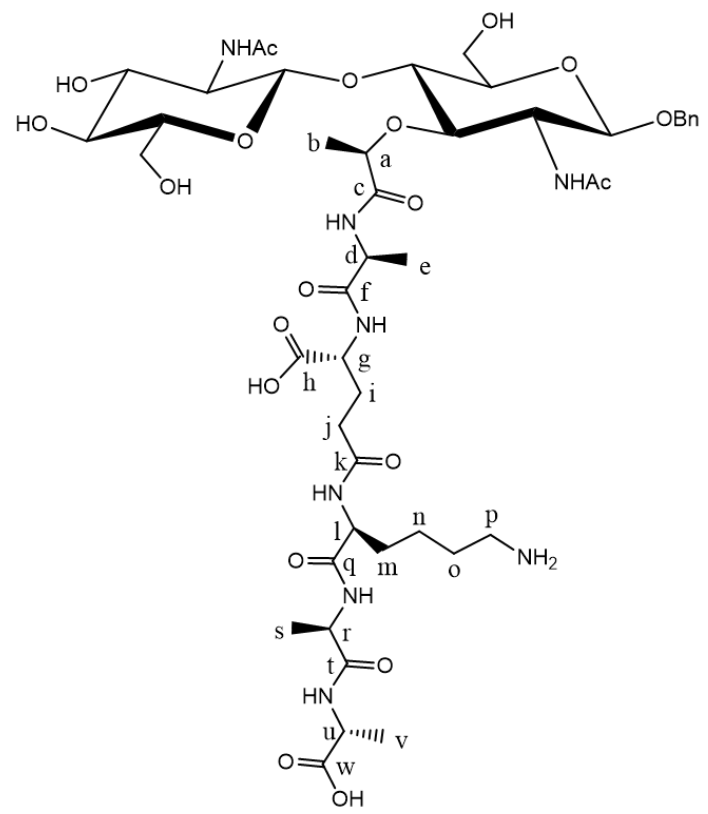


A solution of $6(10.1 \mathrm{mg}, 16.4 \mu \mathrm{mol})$ in THF/1,4-dioxane $/ \mathrm{H}_{2} \mathrm{O}$ [1.33 mL, (0.8:0.4:0.13)] containing $\mathrm{LiOH}\left(66 \mu \mathrm{L}, 1 \mathrm{M}\right.$ in $\left.\mathrm{H}_{2} \mathrm{O}\right)$ was stirred for $3 \mathrm{~h}$ at room temperature. The resulting mixture was neutralized with strong acid cation-exchange resin (Amberlite ${ }^{\circledR}$ IRN-77 $\mathrm{H}^{+}$ form), filtrated and concentrated under reduced pressure, giving crude saponified 6 ( $8.5 \mathrm{mg})$ which was used in the next step without further purification. To an ice-cooled solution of saponified 6 and pentapeptide TFA salt $7(22.8 \mathrm{mg}, 26.7 \mu \mathrm{mol})$ in DMF (1.5 mL) was added a solution of 1-ethyl-3-[3-(dimethylamino)propyl]carbodiimide] (EDC, $6.8 \mathrm{mg}, 44 \mu \mathrm{mol}$ ) and 1-hydroxy-7-azabenzotriazole (HOAt, $6.2 \mathrm{mg}, 45 \mu \mathrm{mol})$ in DMF $(0.12 \mathrm{~mL})$, followed by $N, N$ diisopropylethylamine (DIPEA, $10.1 \mu \mathrm{L}, 58 \mu \mathrm{mol}$ ). After $0.5 \mathrm{~h}$ at $0^{\circ} \mathrm{C}$, the mixture was stirred overnight at room temperature, and then concentrated under reduced pressure, giving benzyl$O$-GlcNAc-MurNAc Fmoc-dimethylpentapeptide. Fmoc removal was realized by dissolving the residue in DMF $(2 \mathrm{~mL})$, piperidine $(5.8 \mu \mathrm{L}, 59 \mu \mathrm{mol})$ was added, and the solution was stirred at room temperature for $8 \mathrm{~h}$. TLC analysis indicating the deprotection being not complete, another addition of piperidine $(5 \mu \mathrm{L}, 50 \mu \mathrm{mol})$ was done and the mixture stirred overnight at room temperature. The mixture was concentrated under reduced pressure, and the residue taken in $\mathrm{H}_{2} \mathrm{O}(1 \mathrm{~mL})$, centrifuged and the filtrate was purified by SEC [ammonium bicarbonate $0.1 \mathrm{M}$ in $\mathrm{H}_{2} \mathrm{O}$ ]. Appropriate fractions were pooled and freeze-dried giving benzyl$O$-GlcNAc-MurNAc dimethylpentapeptide, which was saponified by dissolution in THF/1,4dioxane $/ \mathrm{H}_{2} \mathrm{O}$ [1.46 mL, (0.9:0.45:0.11)] containing $\mathrm{LiOH}\left(116 \mu \mathrm{L}, 1 \mathrm{M}\right.$ in $\left.\mathrm{H}_{2} \mathrm{O}\right)$, and stirring for $7.5 \mathrm{~h}$ at room temperature. The mixture was diluted with $\mathrm{H}_{2} \mathrm{O}(5 \mathrm{~mL})$, neutralized with hydrochloric acid $(50 \mu \mathrm{L}, 1 \mathrm{M})$, then concentrated under reduced pressure, and the residue was purified by SEC [ammonium carbonate $0.1 \mathrm{M}$ in $\mathrm{H}_{2} \mathrm{O}$ ]. Appropriate fractions were pooled and freeze-dried giving benzyl- $O$-GlcNAc-MurNAc pentapeptide 8 (10 mg, 65\%), HRMS (positive ionisation mode) $\mathrm{m} / \mathrm{z}$ 1055.47803, corresponding to $\mathrm{C}_{46} \mathrm{H}_{71} \mathrm{~N}_{8} \mathrm{O}_{20}[\mathrm{M}+\mathrm{H}]^{+}$ (requires m/z 1055.47901), $\delta_{\mathrm{H}}\left[\mathrm{D}_{2} \mathrm{O}\right] 1.37(6 \mathrm{H}, \mathrm{H}-\mathrm{b}$ and $\mathrm{H}-\mathrm{v}), 1.38(3 \mathrm{H}, \mathrm{H}-\mathrm{s}), 1.42(3 \mathrm{H}, \mathrm{H}-$ e), $1.45(2 \mathrm{H}, \mathrm{H}-\mathrm{n}), 1.70(2 \mathrm{H}, \mathrm{H}-\mathrm{o}), 1.79(2 \mathrm{H}, \mathrm{H}-\mathrm{m}), 1.80\left(3 \mathrm{H}, \mathrm{s}, \mathrm{NHCOCH}_{3}^{\mathrm{I}}\right), 1.97$ and $2.12(2 \mathrm{H}, \mathrm{H}-\mathrm{i}), 2.07$ (3 H, s, NHCOCH$\left.{ }_{3}^{\mathrm{II}}\right), 2.32(2 \mathrm{H}, \mathrm{H}-\mathrm{j}), 3.00(2 \mathrm{H}, \mathrm{H}-\mathrm{p}), 3.42\left(1 \mathrm{H}, \mathrm{H}-4^{\mathrm{II}}\right)$, $3.43\left(1 \mathrm{H}, \mathrm{H}-5^{\mathrm{II}}\right), 3.46\left(1 \mathrm{H}, \mathrm{H}-5^{\mathrm{I}}\right), 3.56\left(1 \mathrm{H}, \mathrm{H}-3^{\mathrm{II}}\right), 3.57\left(1 \mathrm{H}, \mathrm{H}-3^{\mathrm{I}}\right), 3.75\left(1 \mathrm{H}, \mathrm{H}-2^{\mathrm{II}}\right), 3.75$ and $3.93\left(2 \mathrm{H}, \mathrm{H}-6 \mathrm{a} 6 \mathrm{~b}^{\mathrm{II}}\right), 3.77\left(1 \mathrm{H}, \mathrm{H}-2^{\mathrm{I}}\right), 3.77$ and $3.96\left(2 \mathrm{H}, \mathrm{H}-6 \mathrm{a} 6 \mathrm{~b}^{\mathrm{I}}\right), 3.86\left(1 \mathrm{H}, \mathrm{H}-4^{\mathrm{I}}\right)$, 4.19 (1 H, H-u ), 4.26 (1 H, H-l), 4.28 (1 H, H-g), 4.29 (1 H, H-d), 4.35 (1 H, H-r), 4.40 (1 H, 
$\mathrm{H}-\mathrm{a}), 4.46\left(1 \mathrm{H}, \mathrm{d}, J_{1,2}=8.4, \mathrm{H}-1^{\mathrm{I}}\right), 4.55\left(1 \mathrm{H}, \mathrm{d}, J_{1,2}=8.3, \mathrm{H}-1^{\mathrm{II}}\right), 4.65$ and $4.87\left(2 \mathrm{H}, \mathrm{d}, J_{\mathrm{H}, \mathrm{H}}\right.$ $\left.=12.5, \mathrm{CH}_{2} \mathrm{Ph}\right), 7.35$ to $7.36(5 \mathrm{H}, \mathrm{Ph}) ; \delta_{\mathrm{C}}\left[\mathrm{D}_{2} \mathrm{O}\right] 16.6(\mathrm{C}-\mathrm{s}), 16.9(\mathrm{C}-\mathrm{e}), 17.0(\mathrm{C}-\mathrm{v}), 17.8(\mathrm{C}-$ b), $22.0(\mathrm{C}-\mathrm{n}), 22.1\left(\mathrm{NHCOCH}_{3}{ }^{\mathrm{II}}\right), 22.3\left(\mathrm{NHCOCH}_{3}{ }^{\mathrm{I}}\right), 26.3(\mathrm{C}-\mathrm{o}), 28.0(\mathrm{C}-\mathrm{i}), 30.4(\mathrm{C}-\mathrm{m})$, 31.6 (C-j), 39.1 (C-p), 49.5 (C-r), 49.8 (C-d), 50.2 (C-u), 53.6 (C-g), 54.0 (C-1), 54.3 (C-2 ), $60.0\left(\mathrm{C}-6^{\mathrm{I}}\right), 56.0\left(\mathrm{C}-2^{\mathrm{II}}\right), 61.0\left(\mathrm{C}-6^{\mathrm{II}}\right), 70.2\left(\mathrm{C}-4^{\mathrm{II}}\right), 71.5\left(\mathrm{CH}_{2} \mathrm{Ph}\right), 73.5\left(\mathrm{C}-3^{\mathrm{II}}\right), 75.4\left(\mathrm{C}-4^{\mathrm{I}}\right)$, $75.2\left(\mathrm{C}-5^{\mathrm{I}}\right), 76.1\left(\mathrm{C}-5^{\mathrm{II}}\right), 78.1(\mathrm{C}-\mathrm{a}), 79.3\left(\mathrm{C}-3^{\mathrm{I}}\right), 100.1\left(\mathrm{C}-1^{\mathrm{I}}\right), 100.5\left(\mathrm{C}-1^{\mathrm{II}}\right), 128.4,128.6$, 128.9, and $136.7(\mathrm{Ph}), 173.1$ (C-t), 174,0 (C-q), $174.0\left(\mathrm{NHCOCH}_{3}{ }^{\mathrm{I}}\right), 174.3$ (C-f), 174.6 $\left(\mathrm{NHCOCH}_{3}{ }^{\mathrm{II}}\right), 174.7(\mathrm{C}-\mathrm{c}), 175.5(\mathrm{C}-\mathrm{k}), 176.6(\mathrm{C}-\mathrm{h}), 178.5(\mathrm{C}-\mathrm{w})$.

\section{References}

1. S. Cottaz, E. Samain, Metab. Eng. 2005, 7, 311-317.

2. T. Yohino, K-I Sato, F. Wanme, I. Takai, Y. Ishido, Glycoconj. J. 1992, 9, 287-291.

3. B. Yu , Q. Ouyang, C. Li, Y. Hui, J. Carbohydr. Chem. 1996, 15, 297-302.

4. J-X He, K. Le Mai Hoang, S.H. Kho, Z. Guo, W. Zhong, K.R.V. Thappeta, R. ZamudioVázquez, S.N. Hoo, Q. Xiong, H. Duan, L. Yang, M.B. Chan-Park, X-W. Liu, Chem. Sci. 2020, 11, 3171-3179.

IV. ${ }^{1} \mathrm{H}$ and ${ }^{13} \mathrm{C}$ spectra of compounds 1-9 


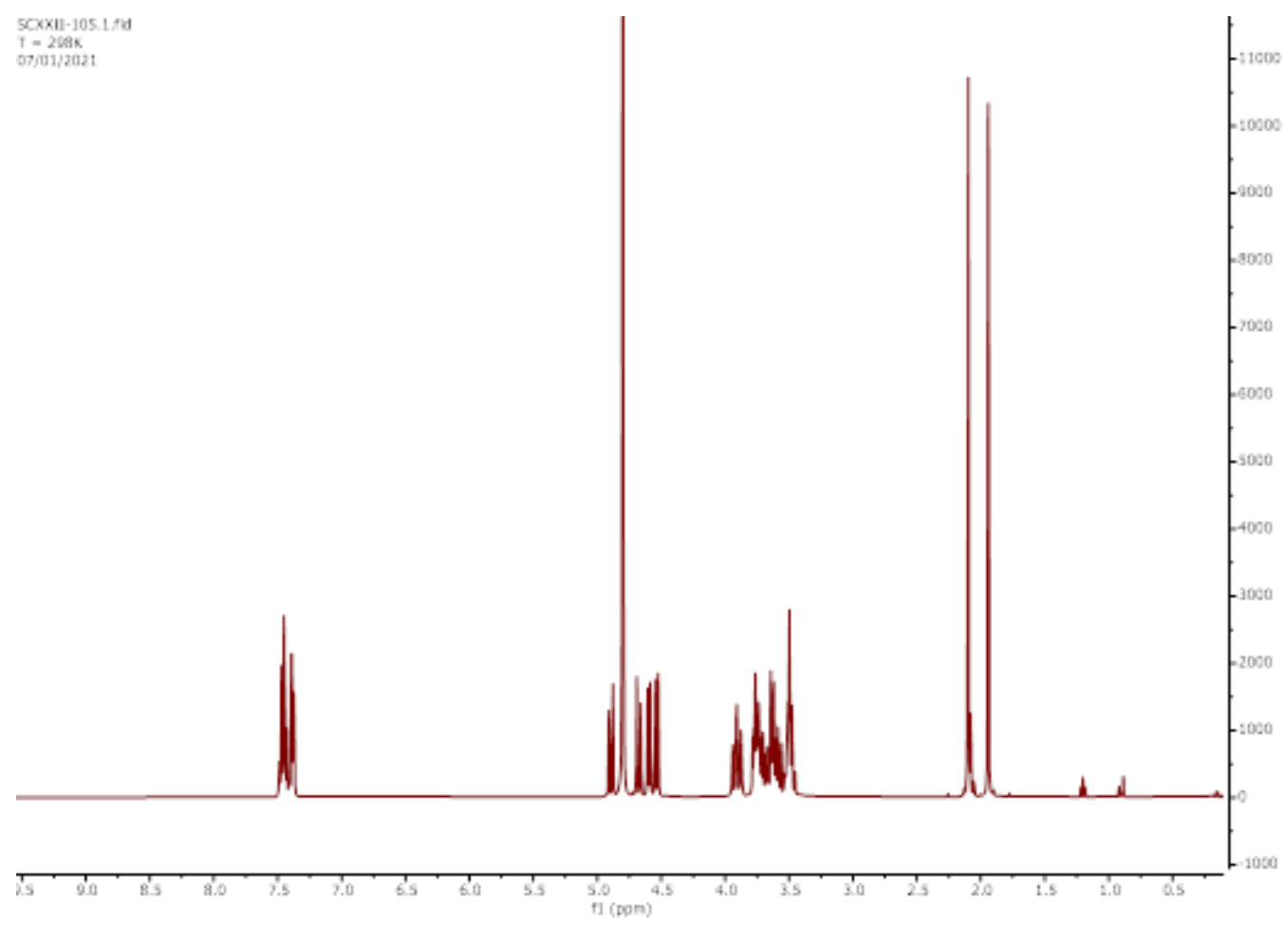

${ }^{1} \mathrm{H}$ NMR of $\mathbf{1}$ in $\mathrm{D}_{2} \mathrm{O}$.

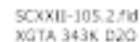

Noth 3435. b2

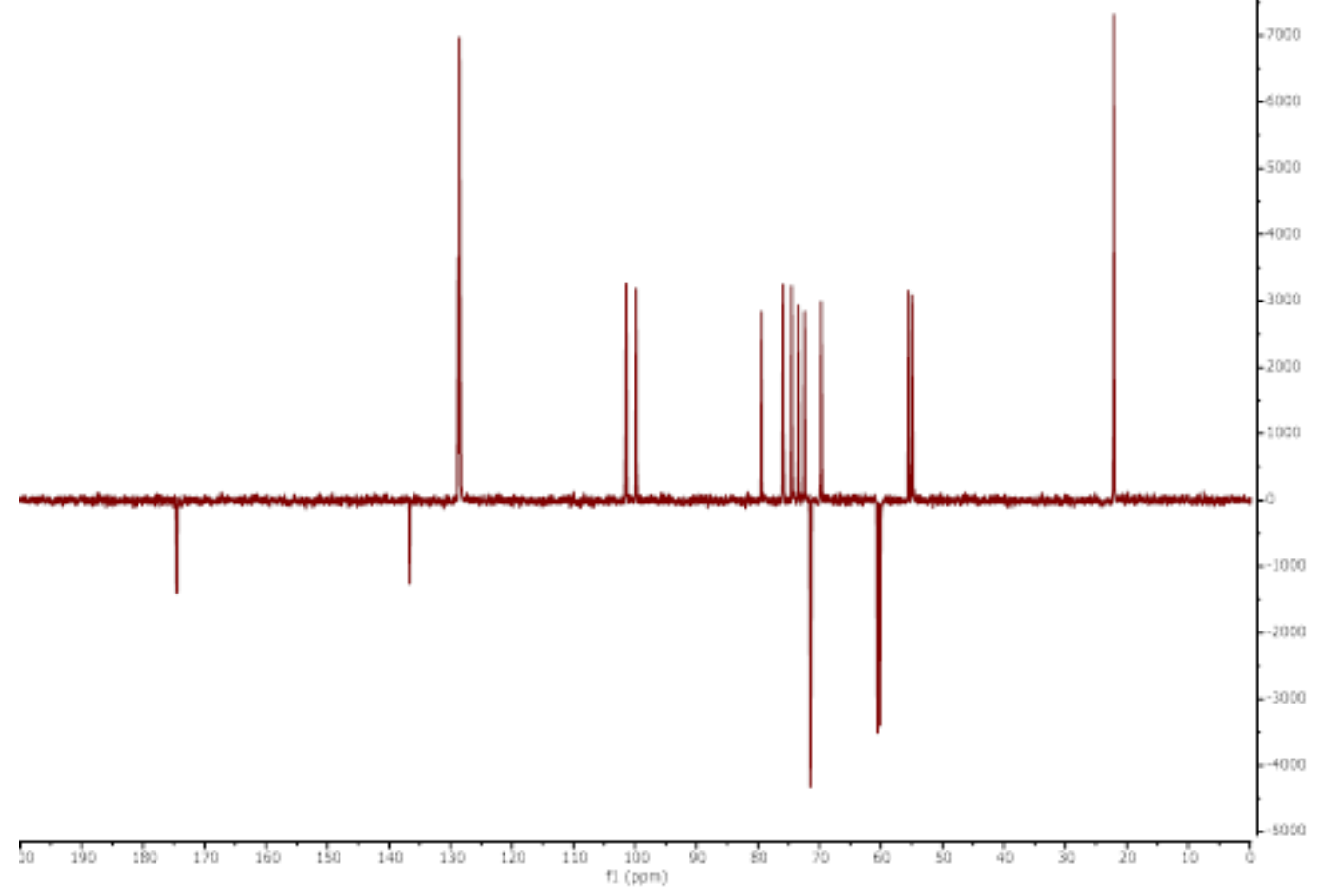

${ }^{13} \mathrm{C}$ DEPTQ 135 NMR of $\mathbf{1}$ in $\mathrm{D}_{2} \mathrm{O}$. 


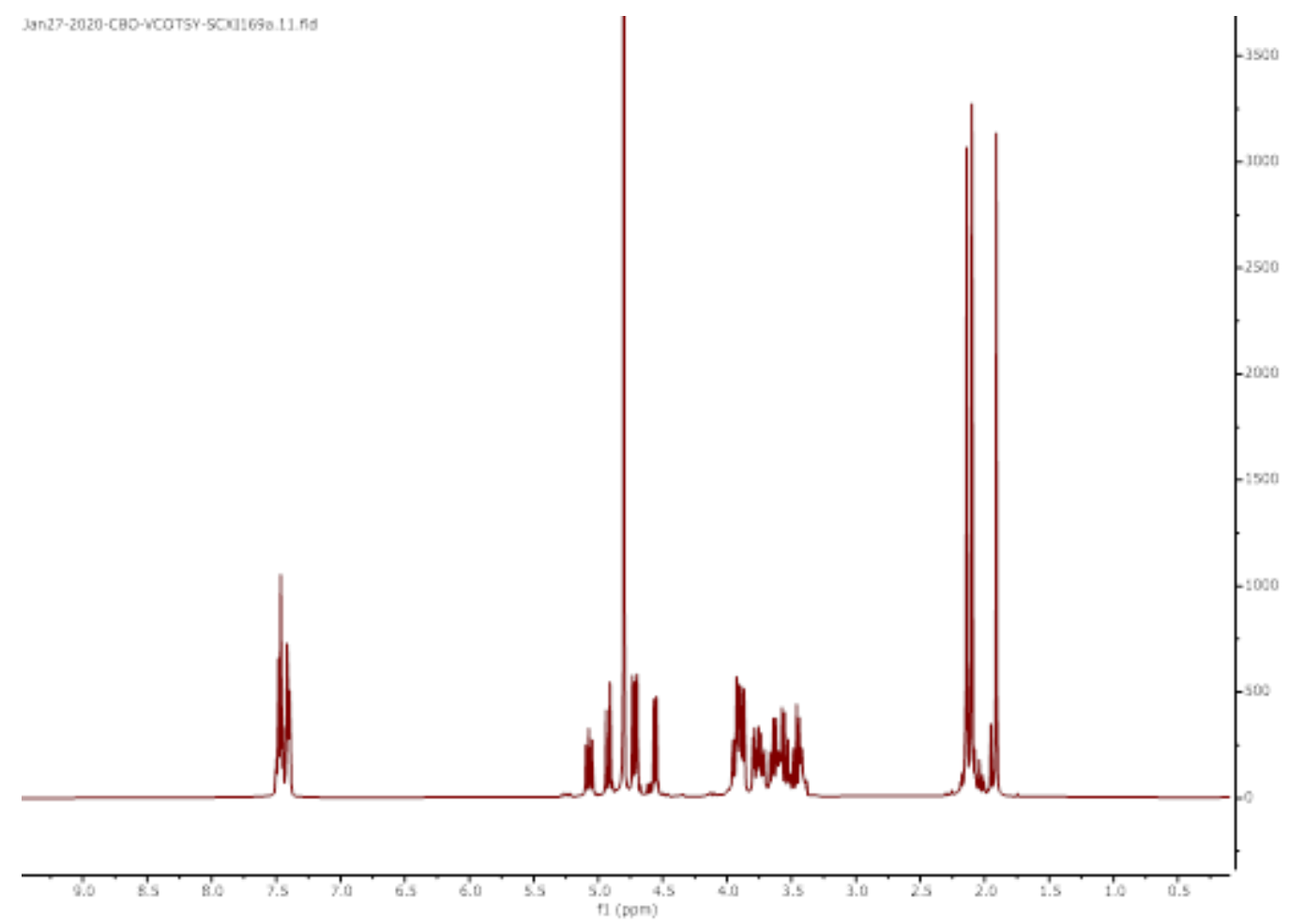

${ }^{1} \mathrm{H}$ NMR of 2 in $\mathrm{D}_{2} \mathrm{O}$.

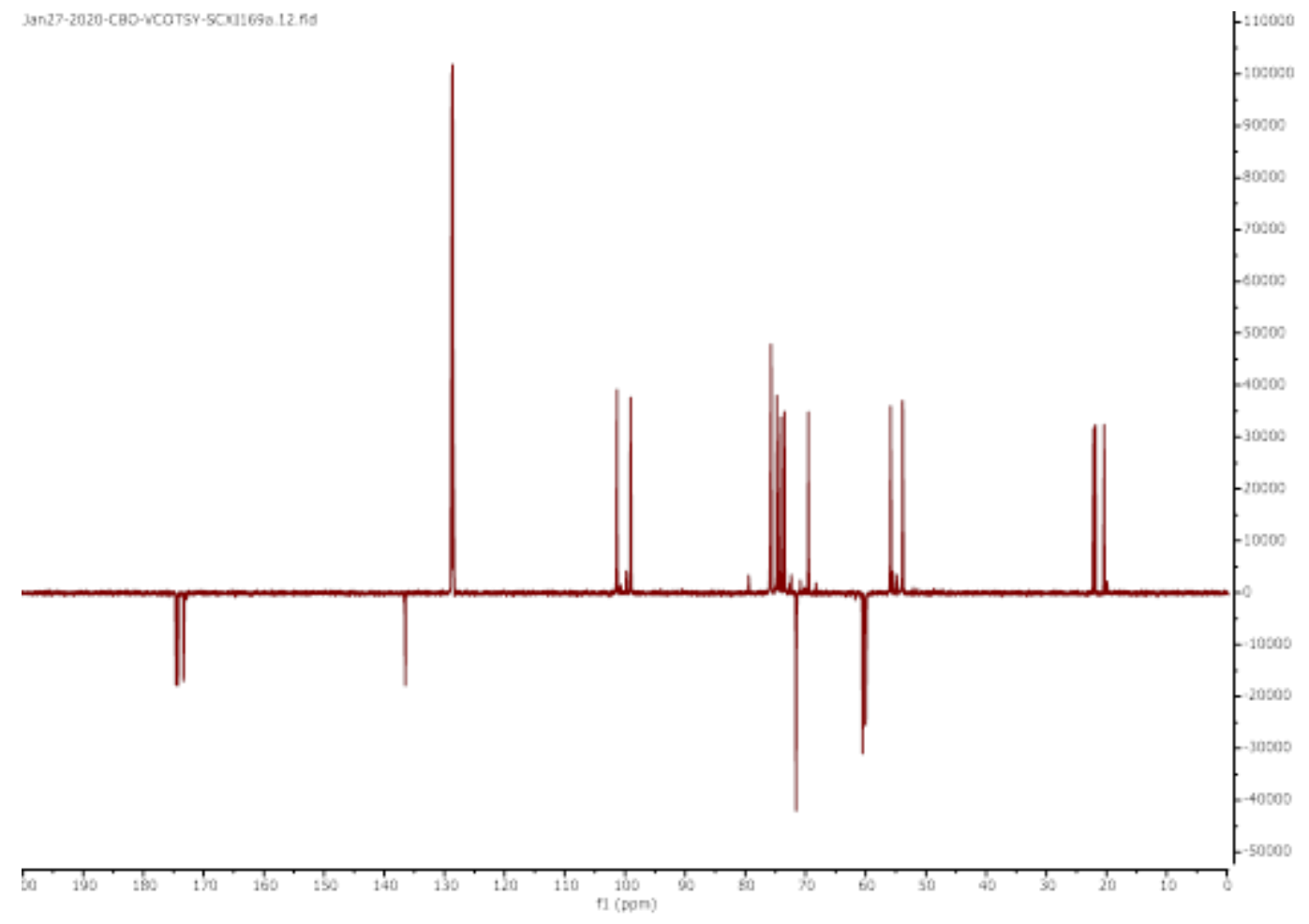


${ }^{13} \mathrm{C}$ DEPTQ $135 \mathrm{NMR}$ of $\mathbf{2}$ in $\mathrm{D}_{2} \mathrm{O}$.

HMBCG

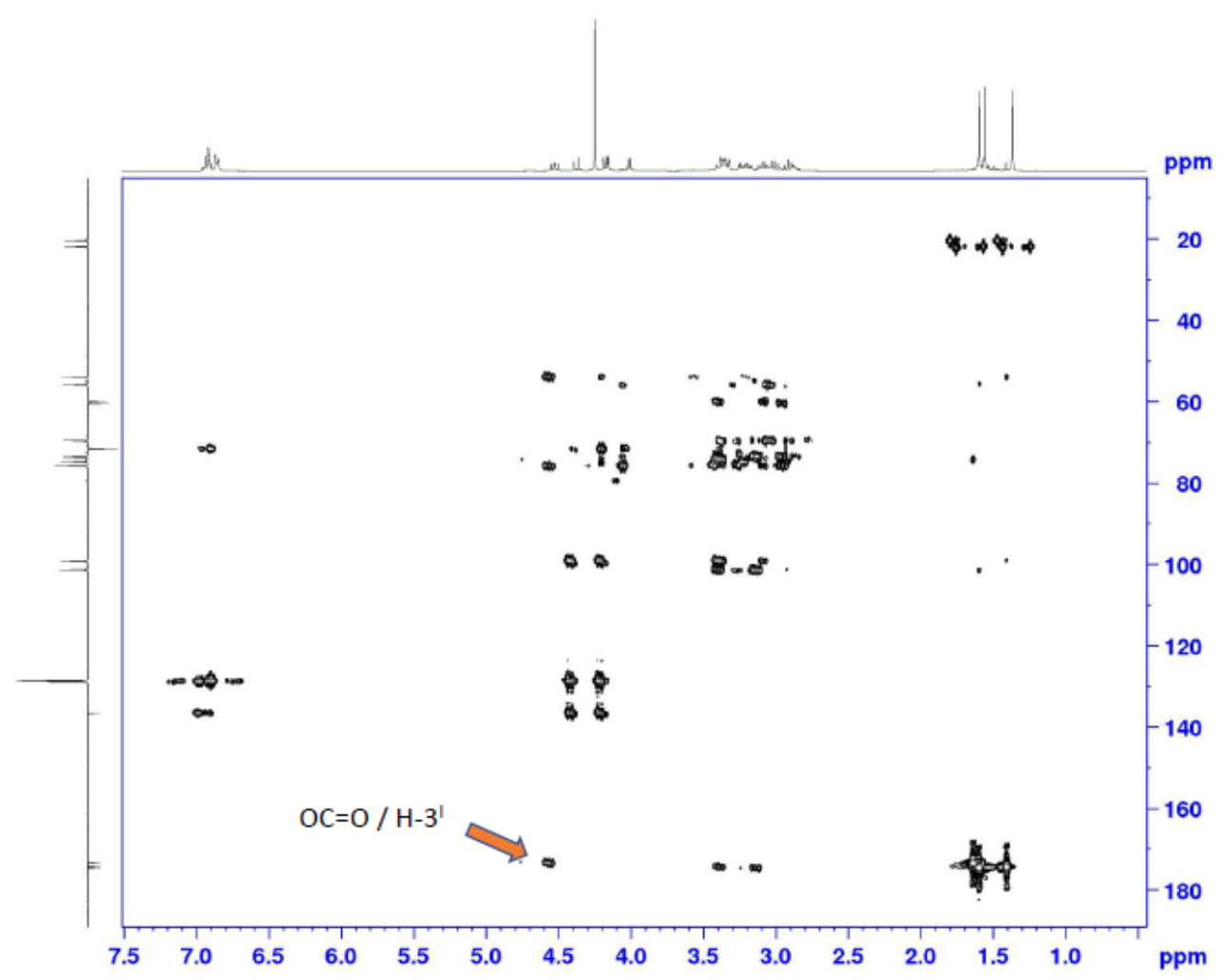

${ }^{1} \mathrm{H}_{-}{ }^{13} \mathrm{C}$ HMBC (Heteronuclear Multiple Bond Connectivity) of 2 in $\mathrm{D}_{2} \mathrm{O}$. Orange arrow highlight the correlation between $O$-acetyl carbonyl and $\mathrm{H}-3$. 


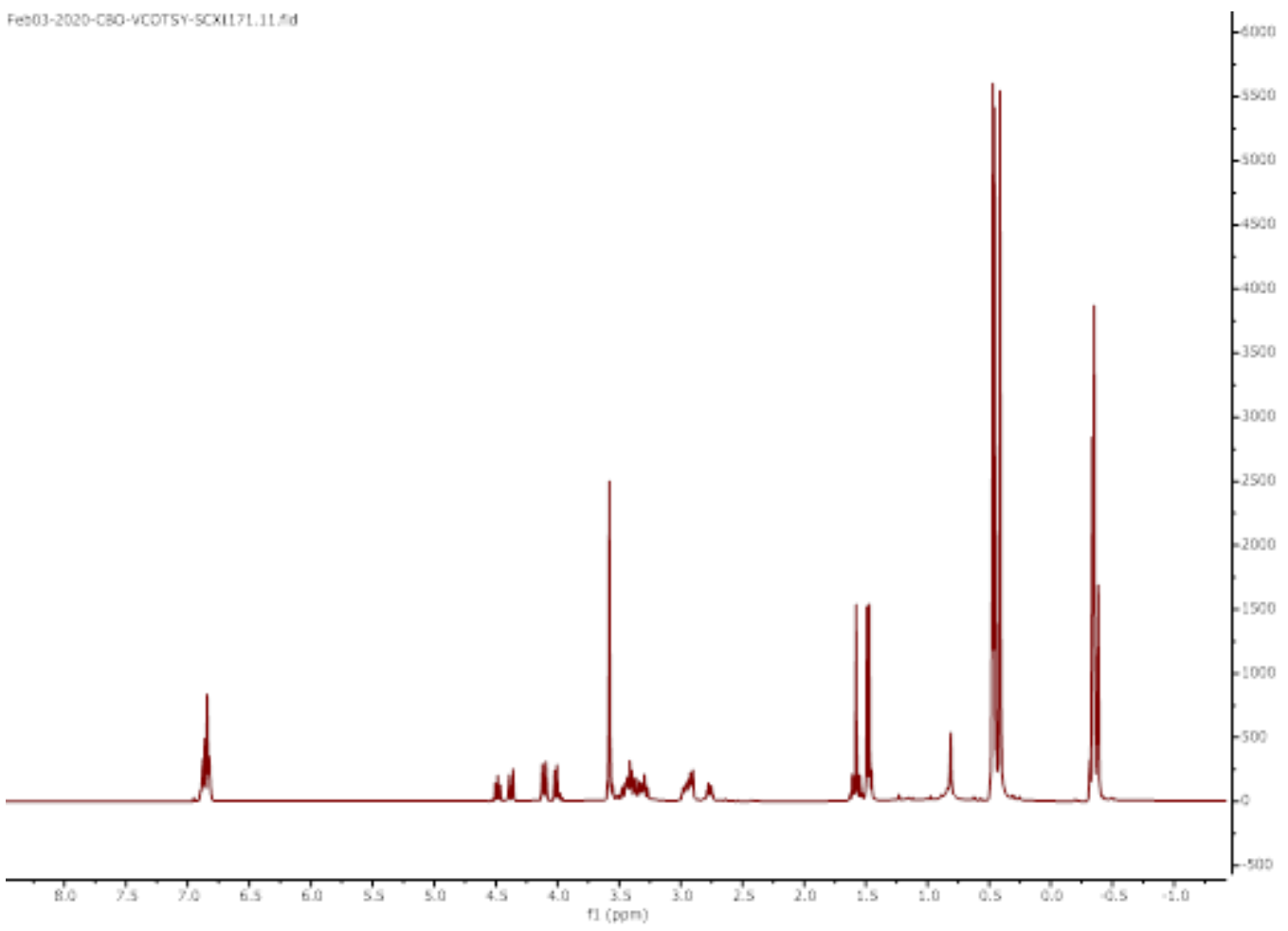

${ }^{1} \mathrm{H}$ NMR of $\mathbf{3}$ in THF- $d_{8}$.

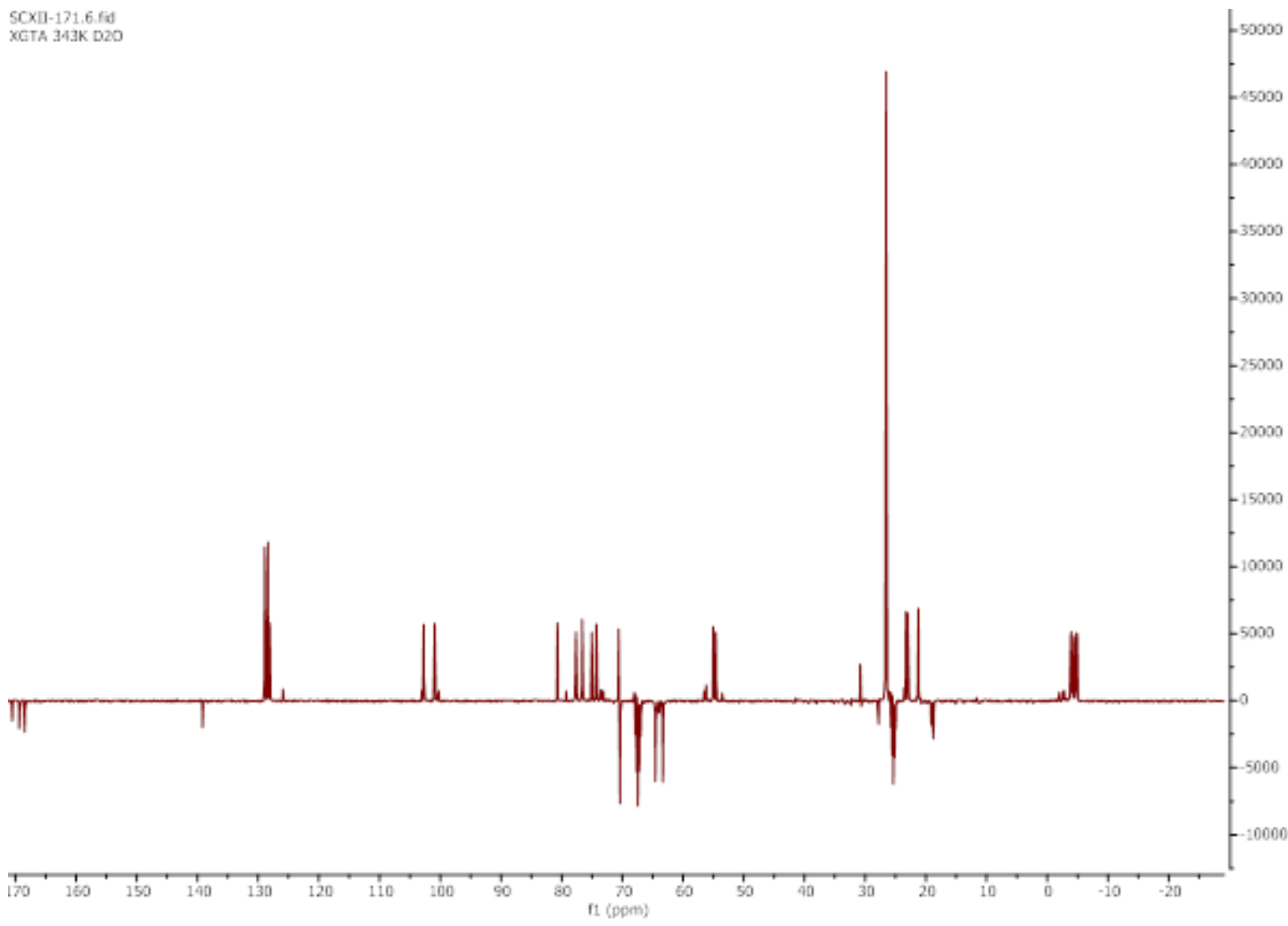

${ }^{13} \mathrm{C}$ DEPTQ 135 NMR of 3 in THF- $d_{8}$. 


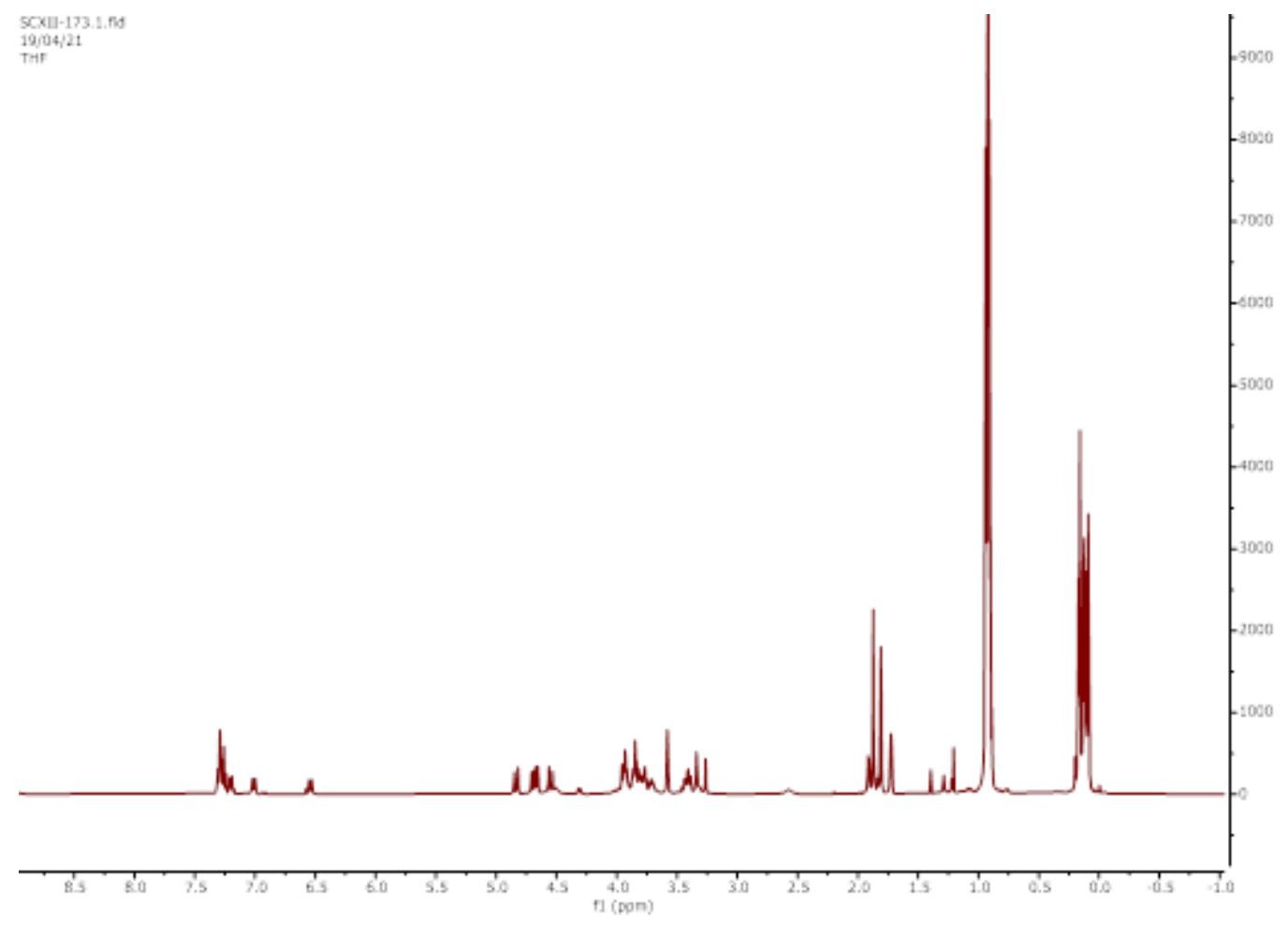

${ }^{1} \mathrm{H}$ NMR of 4 in THF- $d_{8}$.

SCxO-173.9. fod KCTA 3 A3K D2O

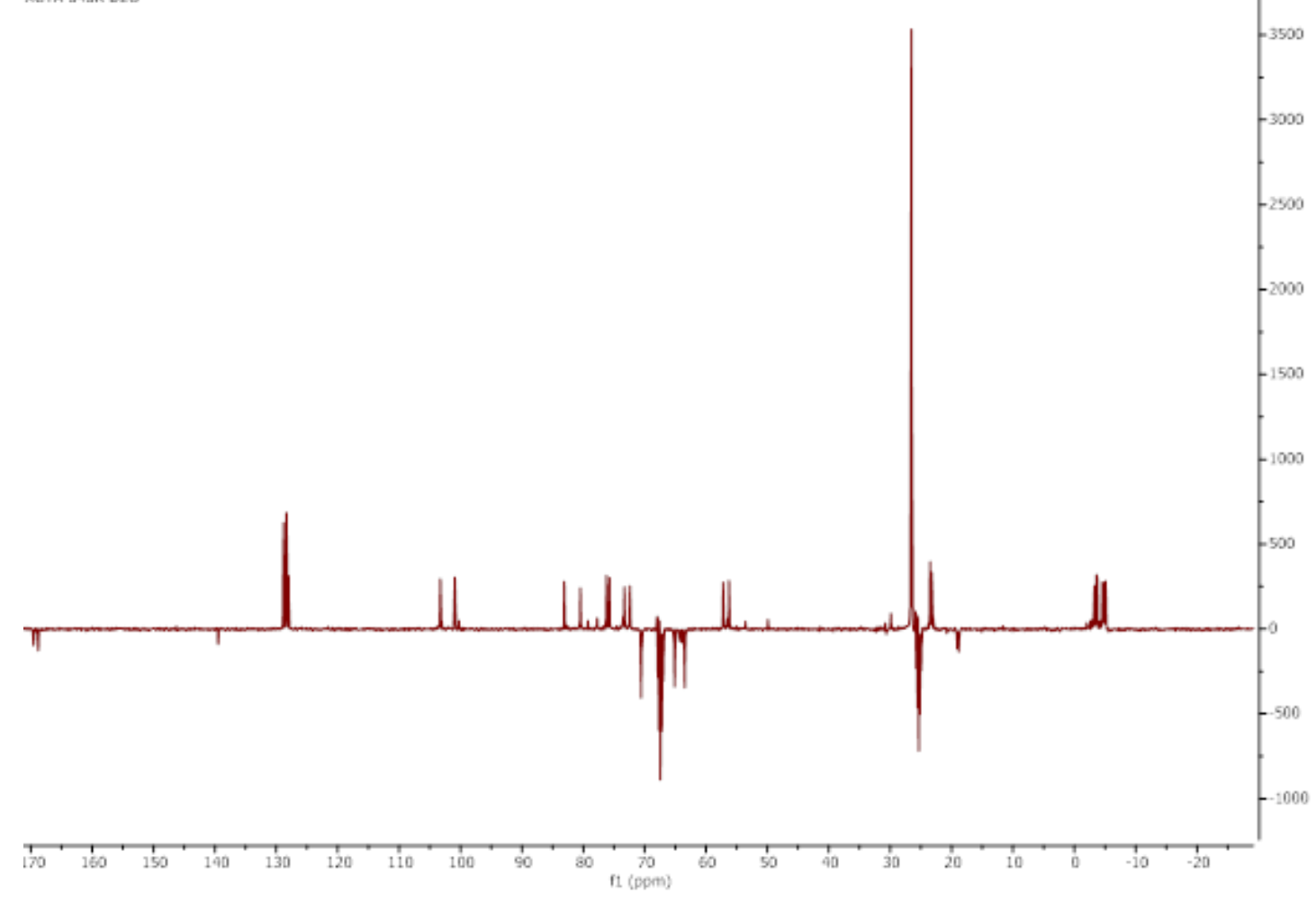

${ }^{13} \mathrm{C}$ DEPTQ 135 NMR of 4 in THF- $d_{8}$. 


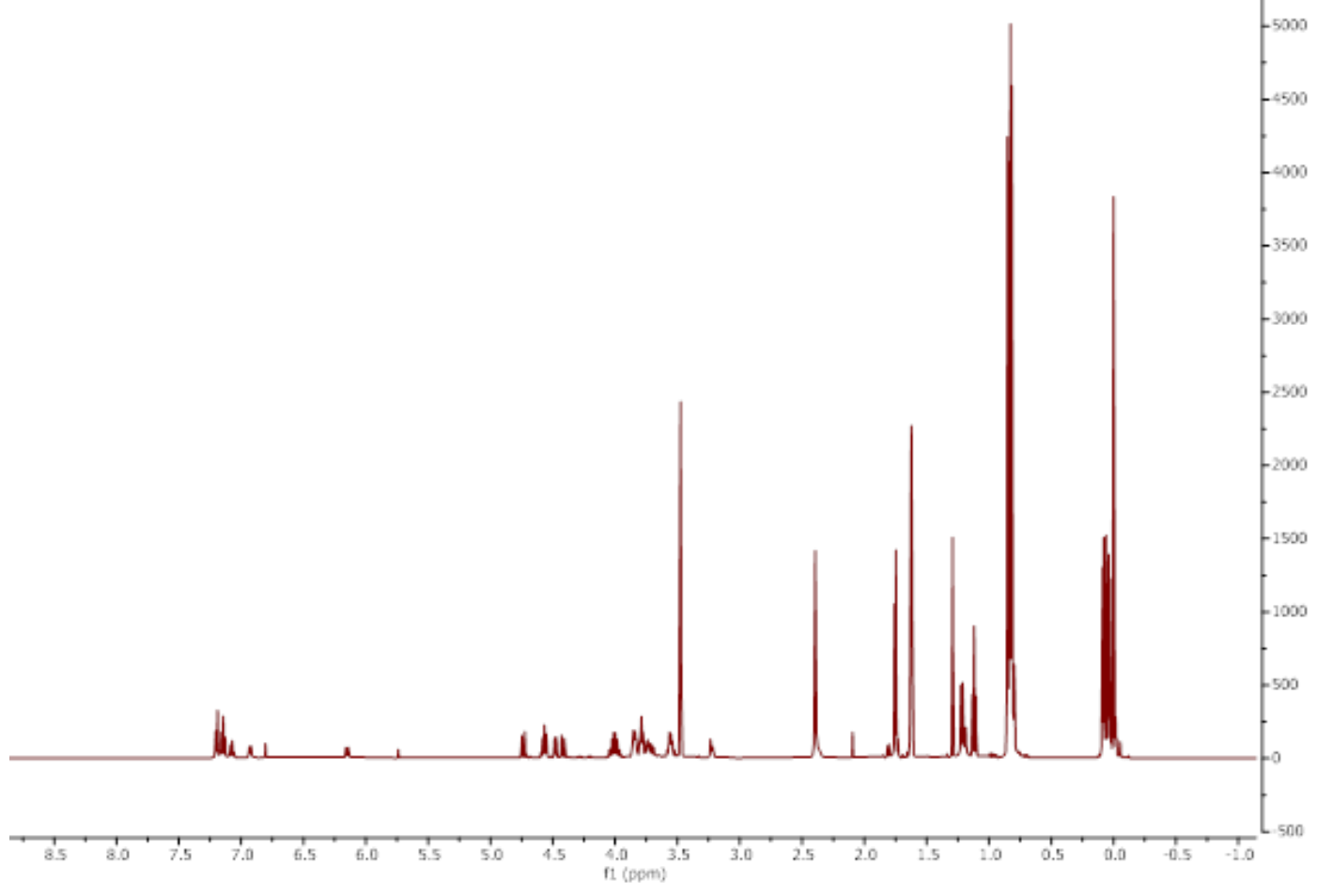

${ }^{1} \mathrm{H}$ NMR of 5 in THF- $d_{8}$.

vcorsy-scoul-177.2.5

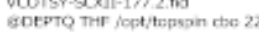

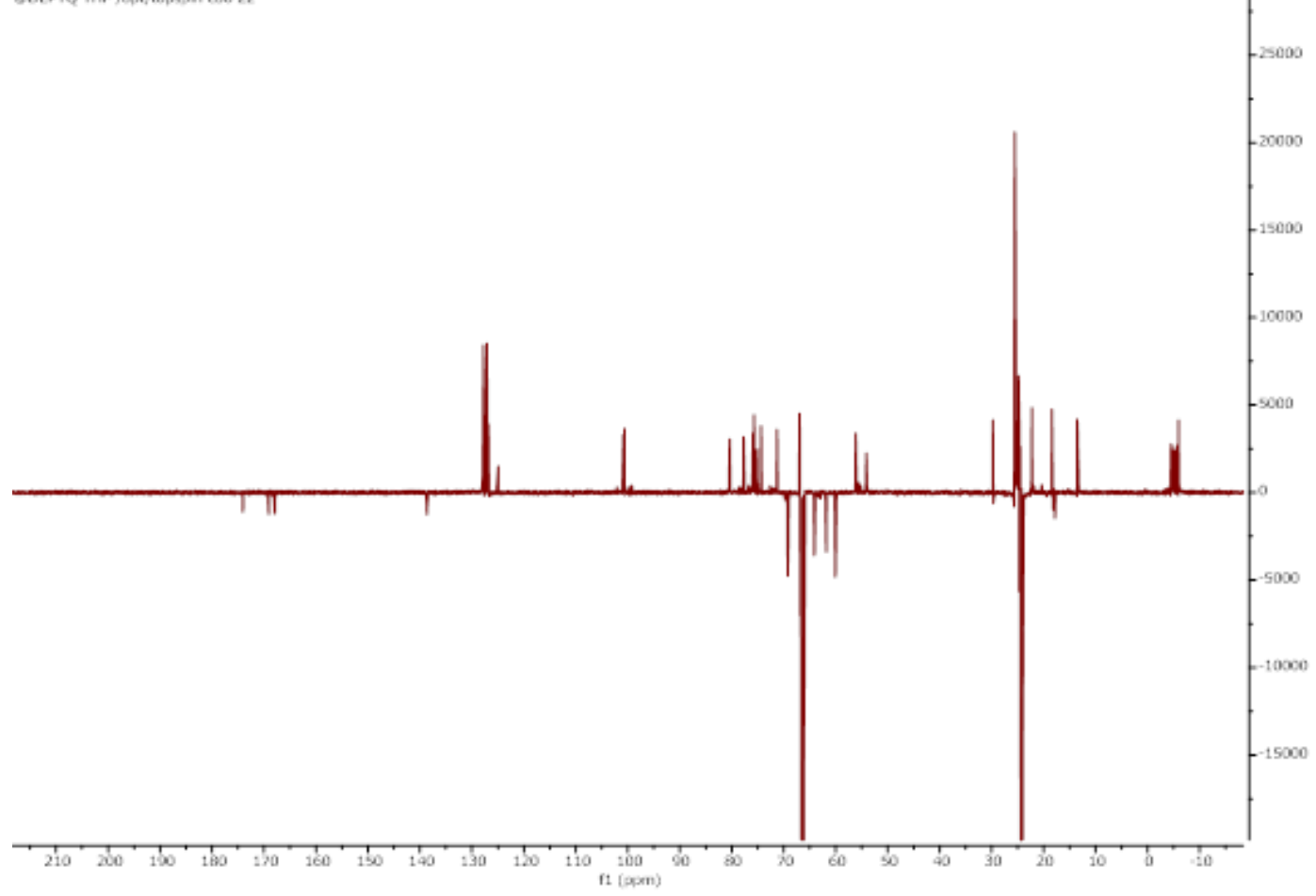

${ }^{13} \mathrm{C}$ DEPTQ 135 NMR of 5 in THF- $d_{8}$. 


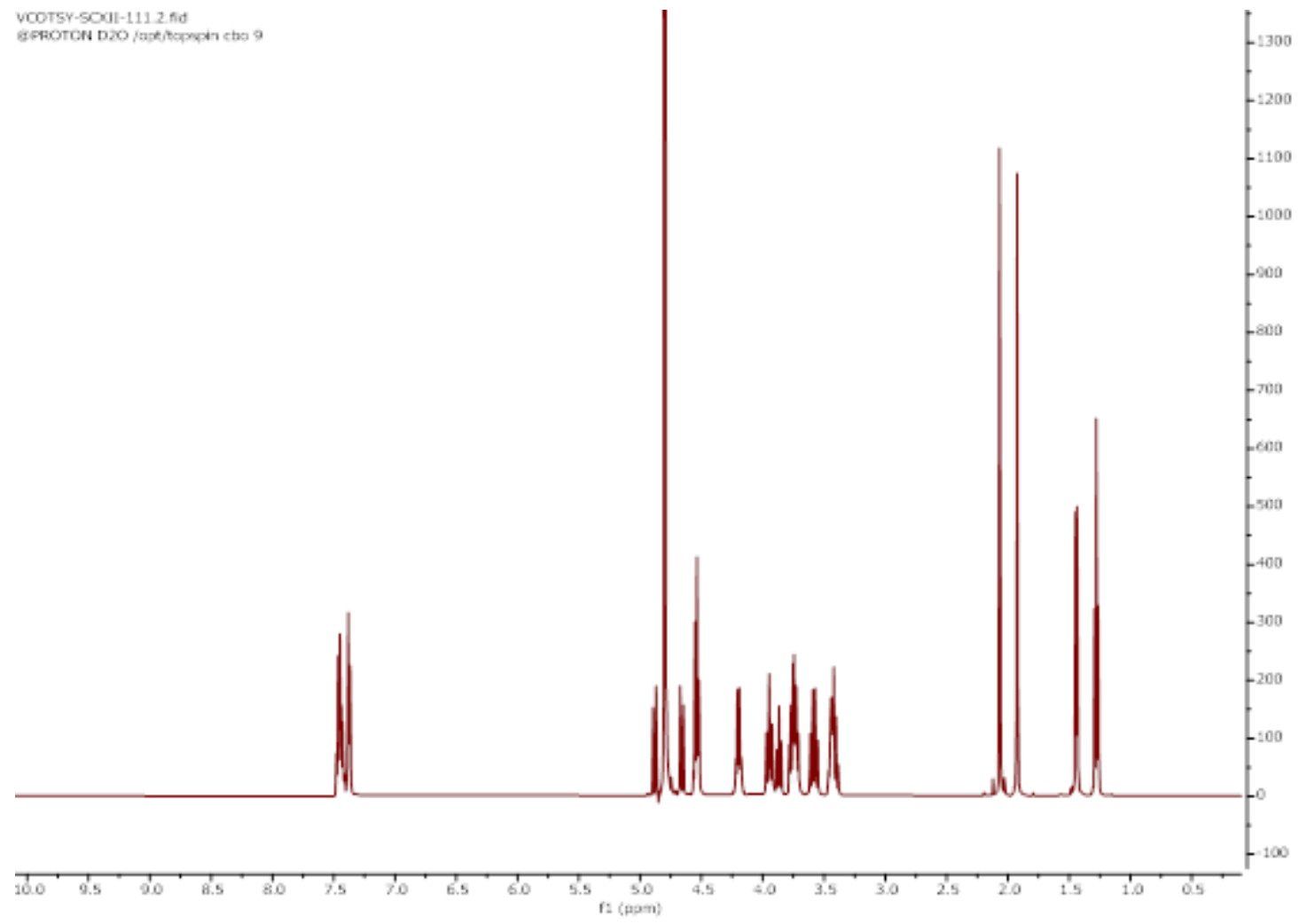

${ }^{1} \mathrm{H}$ NMR of 6 in $\mathrm{D}_{2} \mathrm{O}$.

COTSY-SCXII-111.3Ad

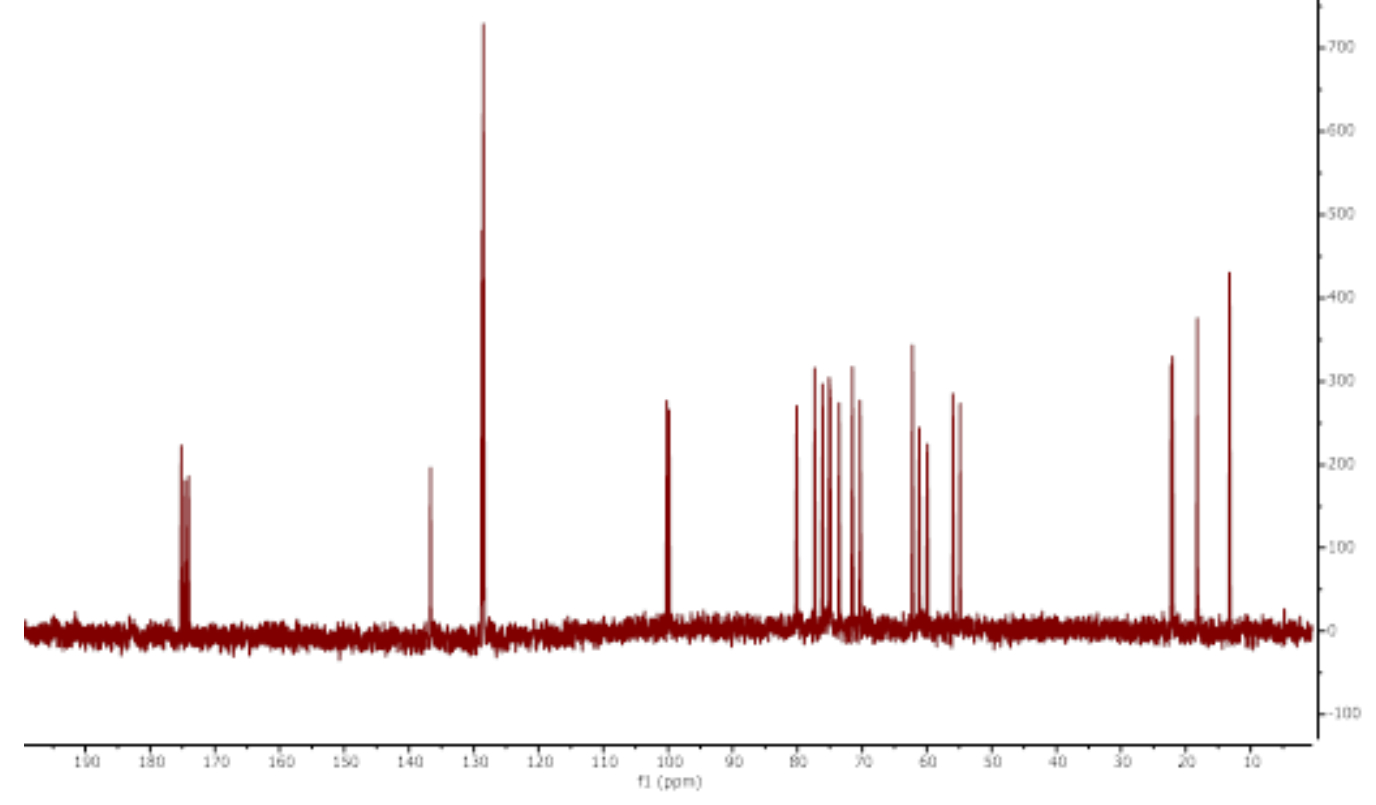

${ }^{13} \mathrm{C}$ NMR of 6 in $\mathrm{D}_{2} \mathrm{O}$. 


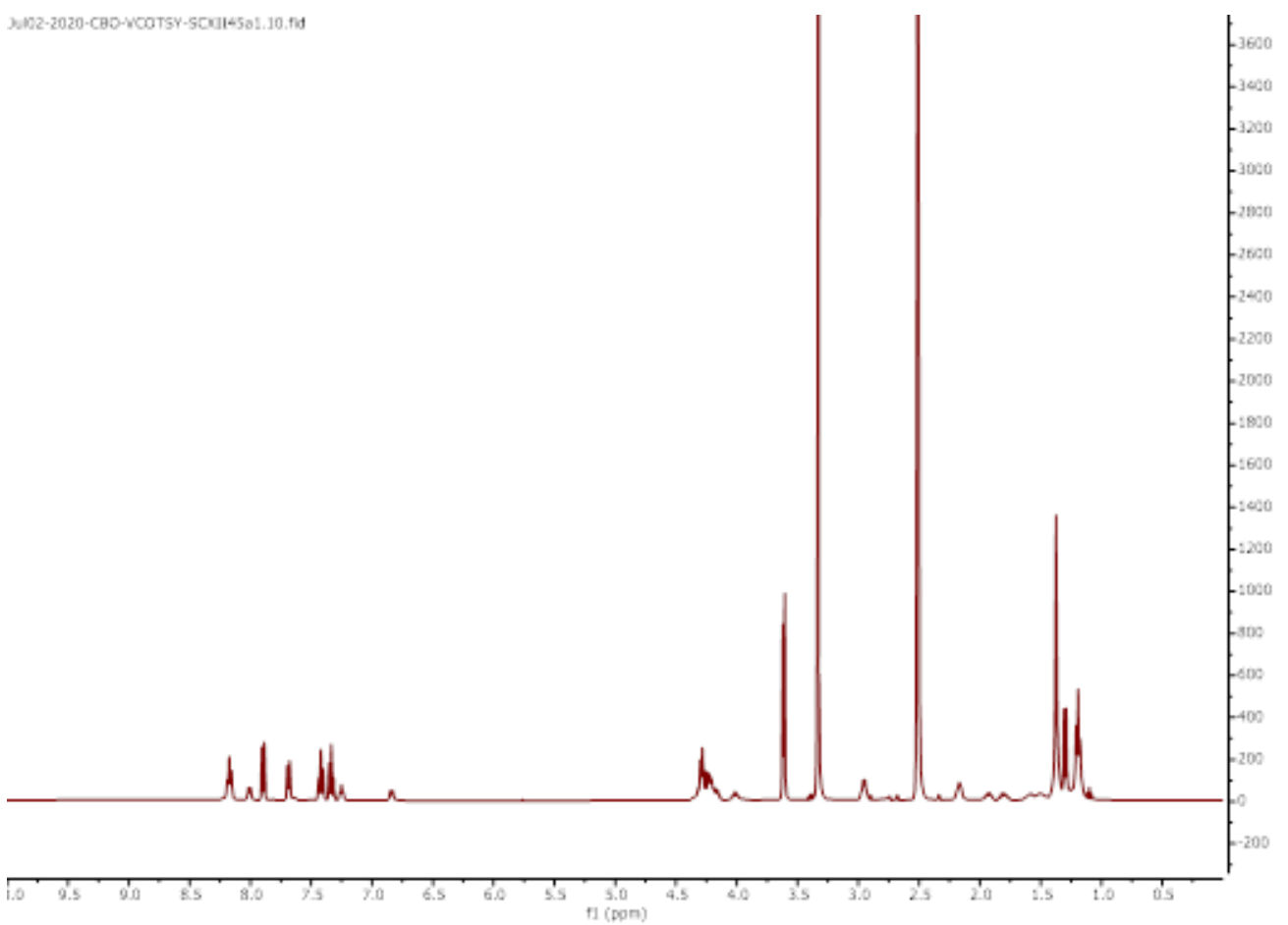

${ }^{1} \mathrm{H}$ NMR of Boc-L-Ala-D-iso-Glu(OMe)-L-Lys(Fmoc)-D-Ala-D-Ala-OMe in DMSO- $d_{6}$.

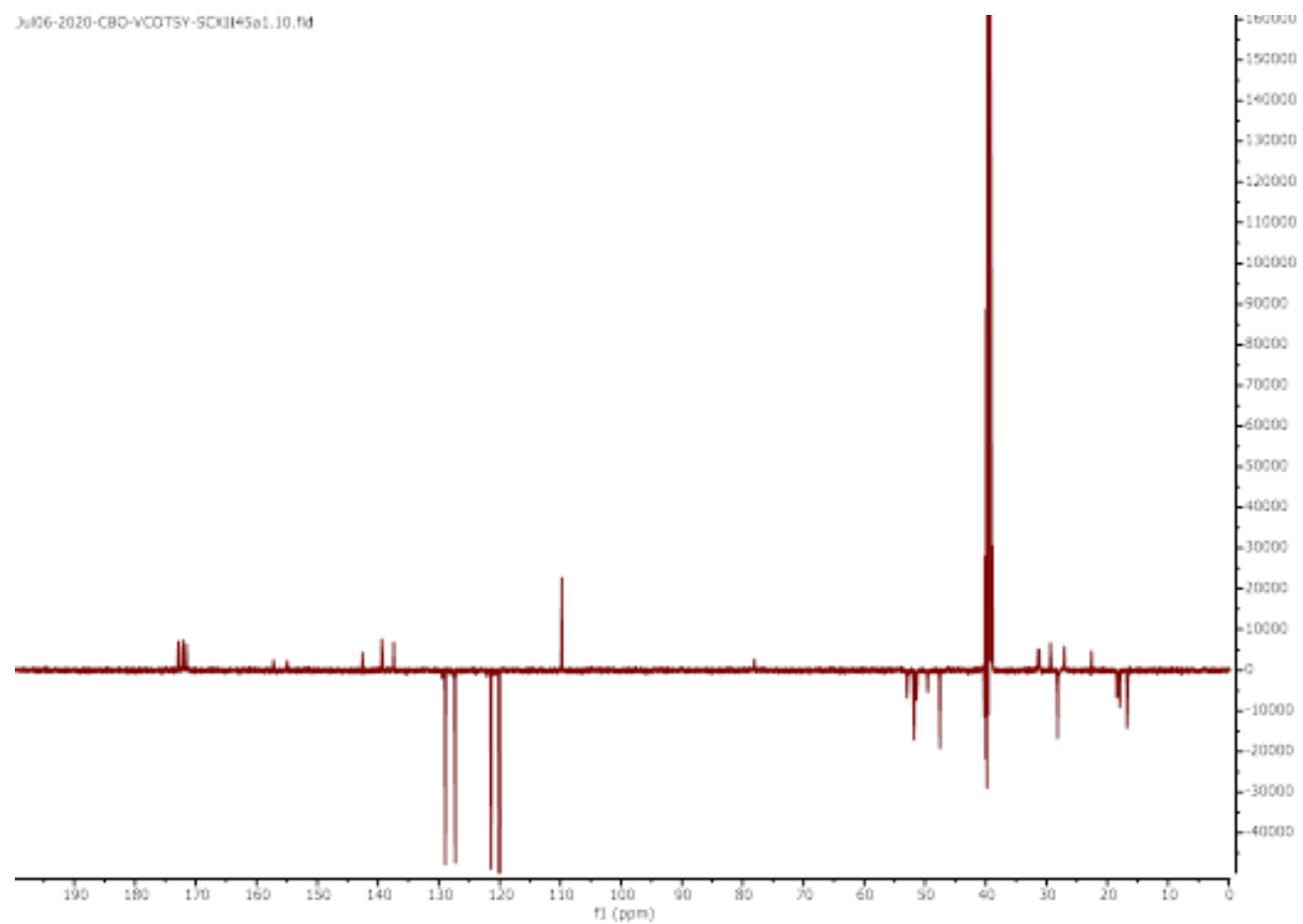

${ }^{13}$ C DEPTQ 135 NMR of Boc-L-Ala-D-iso-Glu(OMe)-L-Lys(Fmoc)-D-Ala-D-Ala-OMe in DMSO- $d_{6}$. 


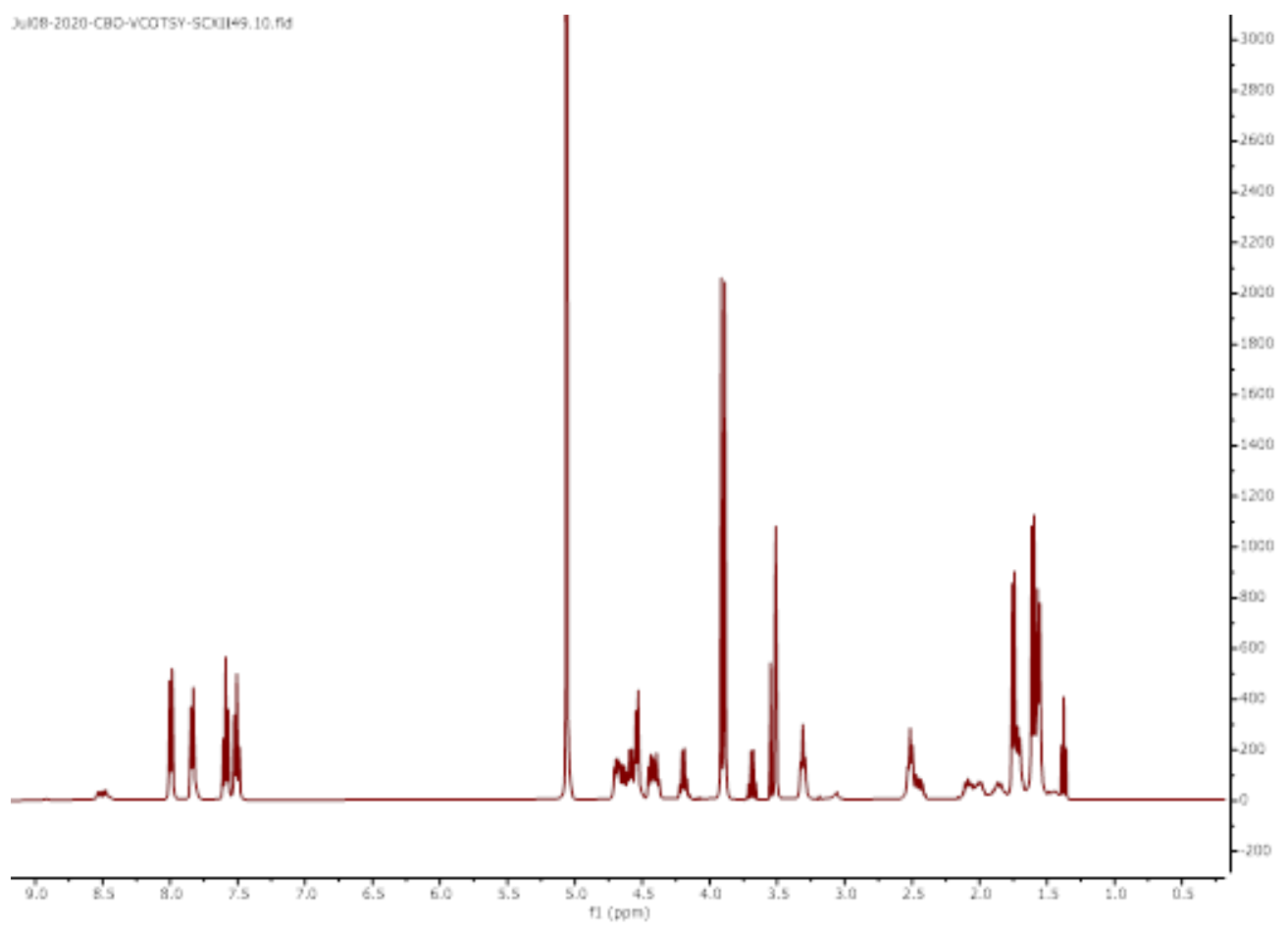

${ }^{1} \mathrm{H}$ NMR of 7 in MeOD.

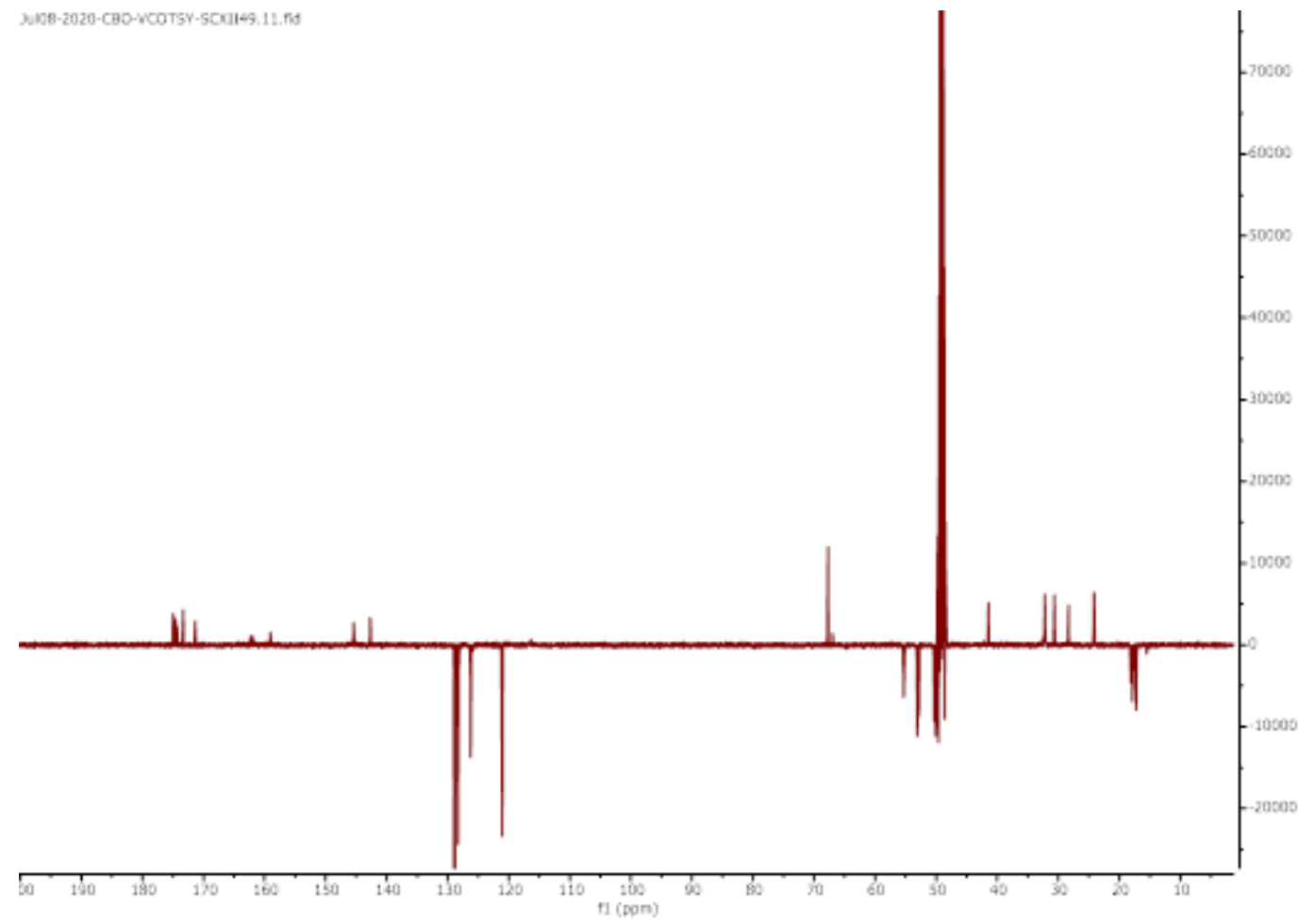

${ }^{13} \mathrm{C}$ DEPTQ 135 NMR of 7 in MeOD. 


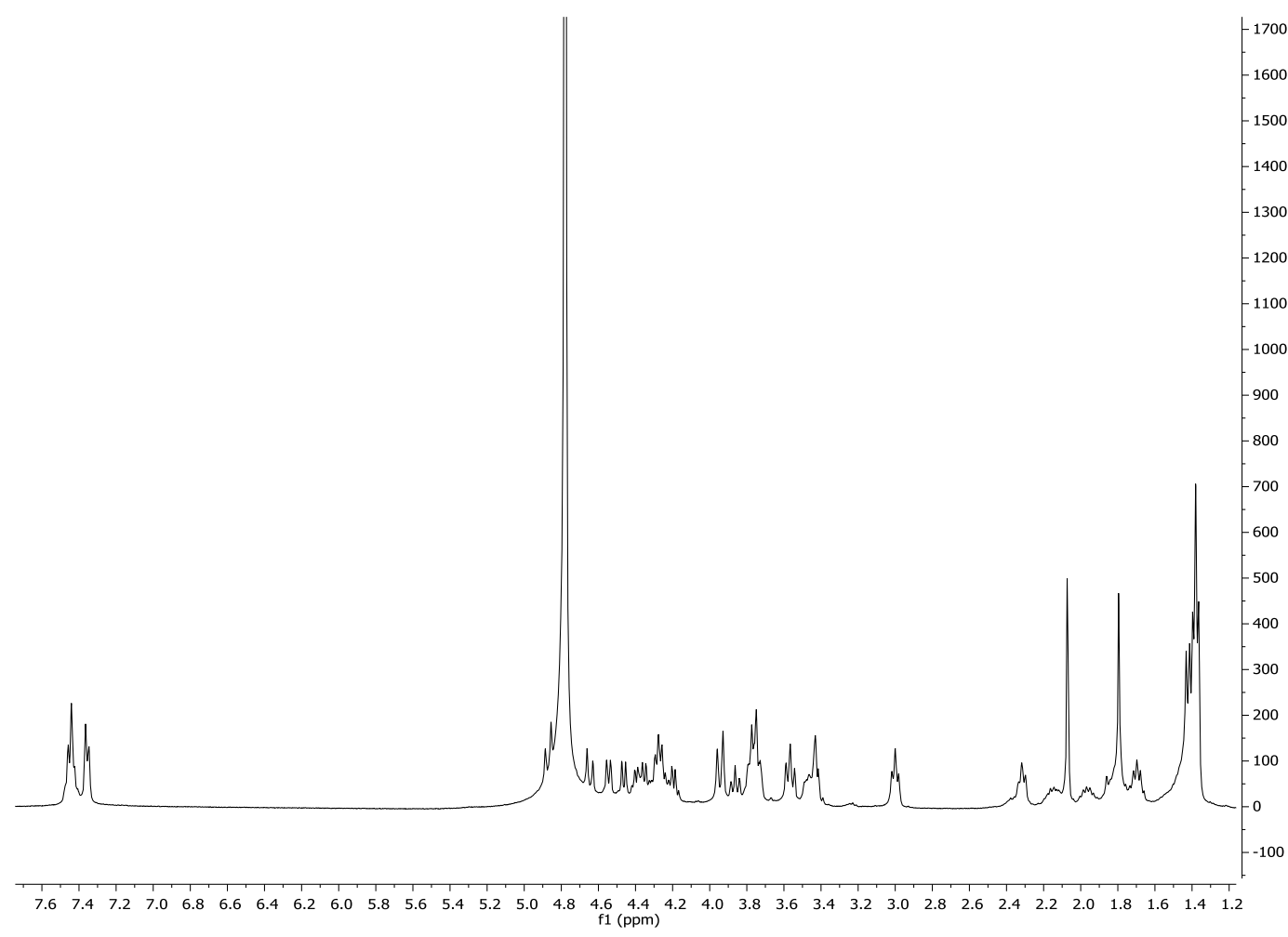

${ }^{1} \mathrm{H}$ NMR of 8 in $\mathrm{D}_{2} \mathrm{O}$.

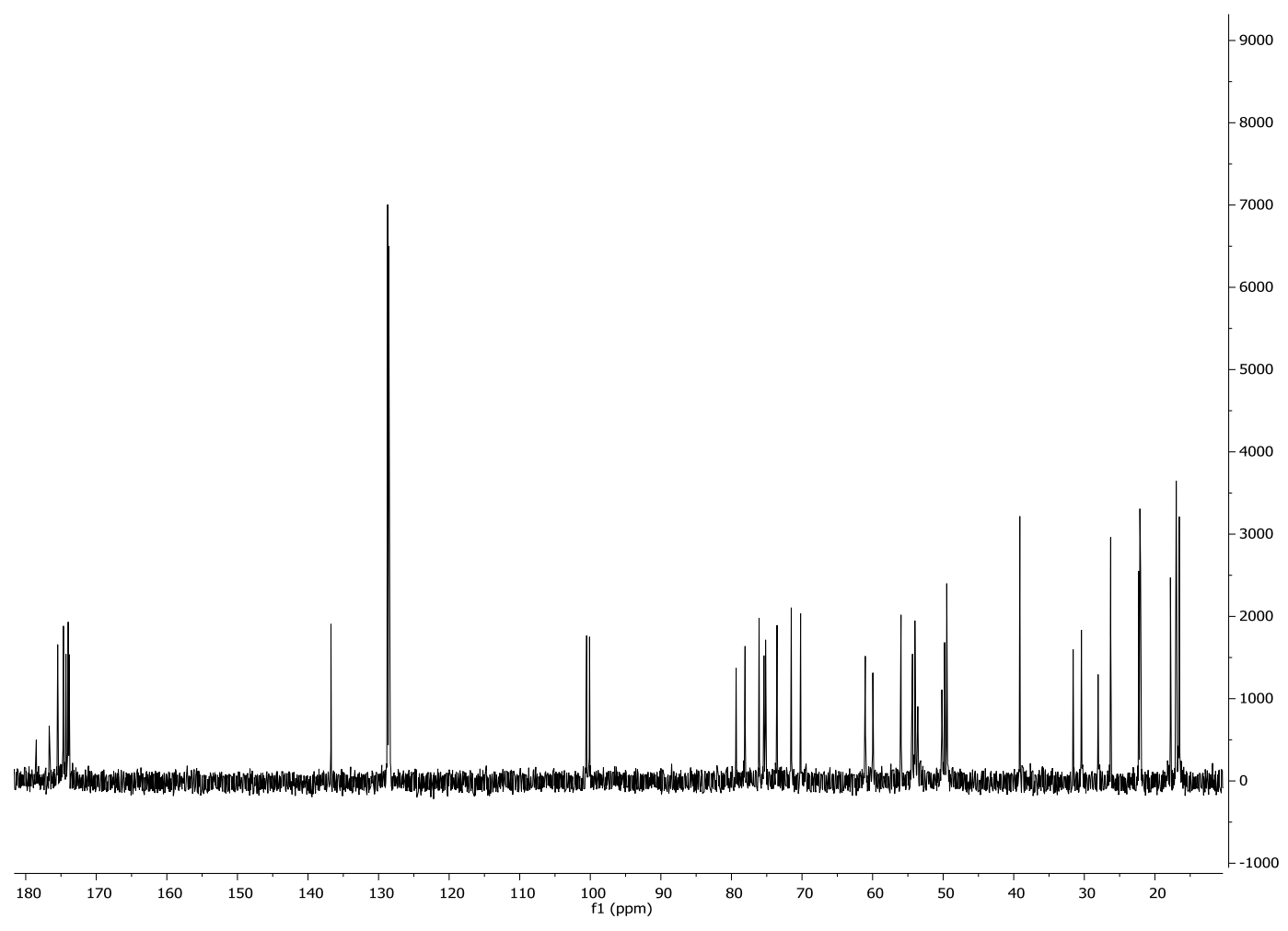

${ }^{13} \mathrm{C}$ NMR of 8 in $\mathrm{D}_{2} \mathrm{O}$. 